bioRxiv preprint doi: https://doi.org/10.1101/2020.11.04.367847; this version posted November 4, 2020. The copyright holder for this preprint (which was not certified by peer review) is the author/funder, who has granted bioRxiv a license to display the preprint in perpetuity. It is made available under aCC-BY-NC 4.0 International license.

\title{
Developmental regulation of mitotic chromosome formation revealed by condensin reporter mice
}

\author{
Gillian C A Taylor ${ }^{1}$, Lewis A Macdonald ${ }^{1}$, Matilda Bui ${ }^{1}$, Lucy Scott ${ }^{1}$, Ioannis Christodoulou ${ }^{1}$, Jimi C Wills ${ }^{2}$, \\ Dimitrios K Papadopoulos ${ }^{1}$, Andrew J Wood ${ }^{1}$,
}
${ }^{1}$ MRC Human Genetics Unit, Institute of Genetics and Molecular Medicine, The University of Edinburgh, Edinburgh, EH4 $2 X U$, UK. ${ }^{2}$ Cancer Research UK Edinburgh Centre, Institute of Genetics and Molecular Medicine, University of Edinburgh, Edinburgh, EH4 $2 X U, U K$.
*Email address for correspondence: andrew.wood@igmm.ed.ac.uk

Germline mutations affecting subunits of condensins I and II cause tissue-specific disease in humans and mice through chromosome segregation failure. However, condensin activity is universally required for chromosome segregation, and hence the developmental basis for these phenotypes is not understood. Using novel transgenic mouse strains, we show that cell-lineage-specific dosage of non-SMC condensin subunits controls the number of catalytically active holocomplexes during different haematopoietic cell divisions in mice. Thymic $\mathrm{T}$ cell precursors load significantly higher levels of both condensin I and II subunits onto mitotic chromosomes compared to B cell or erythroid precursors, and undergo elevated mitotic chromosome compaction. Thymic $\mathrm{T}$ cells also experience relatively greater chromosome instability in a condensin II hypomorphic strain, indicating that genome propagation requires particularly high condensin activity at this stage of development. Our data highlight developmental changes in the mitotic chromosome condensation pathway, which could contribute to tissue-specific phenotypes in chromosome instability syndromes.

\section{Introduction}

At the onset of mitosis, the entire genome is restructured in a process involving two condensin complexes and topoisomerase II ${ }^{1-5}$. This serves several purposes: to shorten chromosomes and prevent their breakage in the cytokinetic furrow, to provide the rigidity necessary to withstand traction forces from the mitotic spindle, and to remove catenations between sister chromatids that arise during DNA replication. Under conditions of condensin or topoisomerase II deficiency, persistent catenations result in the formation of anaphase bridges that impair chromosome segregation and trigger structural rearrangements such as chromothripsis ${ }^{6}$. Accordingly, condensin mutations occur at abovebackground levels in human tumour genomes ${ }^{7}$, and cause haematological malignancy in mice ${ }^{8}$.

Condensins are DNA-dependent motor protein complexes ${ }^{9}$ that are homologous to cohesins and SMC5/6, and play an essential role in cell division in eukaryotes, bacteria and archea ${ }^{10}$. On mammalian chromosomes, condensins form an axial structure from which they extrude linear chromatin fibres into loops 3,4 . When combined with the strand passage activity of topoisomerase II, this provides a mechanism that allows intertwined DNA molecules to be individualised
${ }^{11,12}$. Condensins have 5 core subunits: a heterodimer of structural maintenance of chromosomes proteins (SMC2 and SMC4), a kleisin subunit and two HEATrepeat proteins ${ }^{1,13}$. The $\mathrm{N}$ - and $\mathrm{C}$-termini of the kleisin subunit interact with apposing SMC subunits to form an asymmetric ring-like structure that can tether DNAs at the base of expanding loops 4. SMC proteins possess a DNA-dependent ATPase activity encoded within their globular head domains, which also requires the kleisin and HEAT-repeat subunits ${ }^{14,15}$, and is central to their loop forming activity ${ }^{16,17}$. The HEAT repeat subunits create surfaces for DNA binding, and, together with the kleisin, form a 'safety belt' structure that tethers one side of the loop anchor ${ }^{18}$ to ensure that loop extrusion proceeds in a unidirectional manner ${ }^{4}$

Mammals have two condensin complexes, condensin I and II (Figure 1A), which share the same heterodimer of SMC subunits but contain a distinct set of three associated proteins ${ }^{1}$. These complexes are each essential for cellular proliferation in most cell types that have been studied, but show distinct patterns of subcellular localisation during the cell cycle. In cultured cells, condensin II is present in the nucleus throughout the cell cycle ${ }^{19,20}$ and is loaded onto chromatin following DNA replication ${ }^{21,22}$. Condensin 
bioRxiv preprint doi: https://doi.org/10.1101/2020.11.04.367847; this version posted November 4, 2020. The copyright holder for this preprint (which was not certified by peer review) is the author/funder, who has granted bioRxiv a license to display the preprint in perpetuity. It is made available under aCC-BY-NC 4.0 International license.

I is primarily cytoplasmic during interphase and associates with chromosomes only following nuclear envelope breakdown during prometaphase ${ }^{19,20}$. Condensin II therefore drives the early stages of loop extrusion during prophase and is positioned at the centre of the chromatid axis during prometaphase, when condensin I binds to form nested loops which enable maximal levels of compaction during anaphase 3,23 . In Xenopus egg extracts, the ratio of condensin I to II has been shown to determine the shape of metaphase chromosomes. Ratios favouring condensin I lead to longer and thinner chromosomes, whereas ratios favouring condensin II generate chromosomes that are shorter and thicker ${ }^{24}$.

We and others have previously shown that germline mutations affecting the non-SMC condensin subunits cause tissue-specific developmental abnormalities in humans ${ }^{25,26}$ and mice ${ }^{8,27}$. This poses a paradox, because the core chromosome condensation pathway is not thought to change during cellular differentiation. However, with few exceptions ${ }^{28-32}$, our current understanding of mitotic chromosome condensation originates from studies performed in vitro, or in cell lines kept in long-term culture ${ }^{33}$. The aim of the current study was to compare the dynamic properties of condensins I and II across different cell divisions and lineages within a complex tissue, and to establish the relationship between condensin dynamics, mitotic chromosome compaction and condensin mutant phenotypes during development.

\section{Results}

\section{Generation of fluorescent reporter mice for condensin I and II}

In order to measure how the expression level and molecular dynamics of condensin complexes change during different mitotic cell cycles, we generated transgenic reporter mice (Figure 1B, Supplemental Methods). The kleisin subunits Ncaph and Ncaph2 were selected for tagging as they are known to be essential for the function of mouse condensins I and II, respectively ${ }^{34,35}$, and are expressed at levels that are limiting for holocomplex assembly ${ }^{23}$. Ncaph and Ncaph2 therefore serve as proxies for condensin I and II, respectively ${ }^{23}$.

Using a CRISPR-Cas9-based strategy ${ }^{36}$ (Materials and Methods), the mClover coding sequence was integrated at the endogenous Ncaph and Ncaph2 loci for C-terminal tagging (Figure 1B). In line with previous studies utilising tagged kleisin subunits $3,23,37$, this did not affect the expression (Figure $1 C$ ), or localisation (Figure 1D) of fusion proteins.
Crosses of heterozygous transgenic parents produced homozygotes at the expected mendelian frequency (Figure 1E). This contrasts with null mutations in each gene, which are homozygous embryonic lethal ${ }^{34,35}$.

The Ncaph transgene did not significantly affect fertility (Figure $1 \mathrm{~F}$ ) or growth (Figure $1 \mathrm{G}$ ) in the homozygous state, but Ncaph2 homozygotes showed modest reductions in both traits (Figure $1 F \& 1 G$ ). No other developmental abnormalities were apparent in either line. In particular, thymocyte development, which was previously shown to be perturbed by a missense mutation in Ncaph2 (I15N, 8,27), was unaffected in mice homozygous for either transgenic allele (Figure $\mathrm{S} 1$ ). We conclude that the essential functions of Ncaph and Ncaph 2 are retained in the presence of $\mathrm{C}$-terminal mClover tags.

\section{Cell lineage-specific differences in Ncaph and} Ncaph2 expression

Condensin dynamig behaviours have been well documented in cancer cell lines 1,19,20,38. However, whether the cellular activity of these complexes is modulated during different physiological cell cycles, as cells progress along distinct lineage paths within tissues, is not known. To address this question we chose to focus on blood development, where cell types with high mitotic activity can be identified in several functionally specialised cell lineages, each descended from the same pool of tissue stem cells.

Multiparametric flow cytometry was used to compare steady-state levels of Ncaph and Ncaph2 in haematopoietic progenitor and precursor cells that were freshly isolated from the bone marrow and thymus of young adult animals (Figure 2A, Figure S2). DNA content staining was used to selectively assess cells during the S/G2/M phases of the cell cycle (Figure $2 \mathrm{~A})$, thereby controlling for differences in the fraction of $\mathrm{G} 0$ versus $\mathrm{G} 1$ cells across different populations. This analysis revealed that Ncaph protein levels differed by more than 8 -fold between cell types, with lowest levels in early haematopoietic progenitors (LSK: Lin-/Sca$1+/ \mathrm{c}-\mathrm{Kit}+$, including haematopoietic stem cells and their multipotent derivatives), intermediate levels in bone marrow B cell (CD19+) and erythroid lineage (Ter119+) precursors, and highest levels in thymic $\mathrm{T}$ cells (Figure 2B). Ncaph2 protein was also most abundant during divisions in the $\mathrm{T}$ cell lineage (Figure 2C). Importantly, these cell-type differences were not due to changes in the distribution of cells across the $\mathrm{S} /$ $\mathrm{G} 2 / \mathrm{M}$ phases between cell lineages, as they were also apparent when phase-matched cells were compared directly (Figure S3). 
bioRxiv preprint doi: https://doi.org/10.1101/2020.11.04.367847; this version posted November 4, 2020. The copyright holder for this preprint (which was not certified by peer review) is the author/funder, who has granted bioRxiv a license to display the preprint in perpetuity. It is made available under aCC-BY-NC 4.0 International license.

The ratio of condensin I to II has been shown to play a major role in shaping mitotic chromosomes in Xenopus egg extracts ${ }^{24}$, but whether this ratio changes during multicellular development has not been assessed. Our experiments revealed that Ncaph and Ncaph2 were present at roughly equal levels in multipotent progenitors, but Ncaph was approximately 4 -fold more abundant than Ncaph2 in all three lineage-committed populations (Figure 2D), which is similar to the ratio reported recently in HeLa cells ${ }^{23}$. In summary, the absolute expression of kleisin subunits from both condensin complexes changes significantly over different haematopoietic cell cycles, with highest levels of both complexes in thymic $\mathrm{T}$ cells. Furthermore, upregulation of condensin I during haematopoietic differentiation increases the cellular ratio of condensin I relative to condensin II upon lineage commitment.

The level, but not localisation, of kleisin proteins, differs between haematopoietic cell divisions.

To investigate subcellular localisation of condensins in primary blood cells, primary B cell (B220+, 'pre-B') and erythroid (Ter119+, 'pre-E') precursors were isolated by magnetic activated cell sorting (MACS) of freshly dissociated bone marrow tissue, as well as $\mathrm{T}$ cell precursors from freshly dissociated thymus ('pre-T'). Immunophenotyping of mitotic cells within each population revealed that mitotic thymocytes were predominantly at the CD4+CD8+ stage (Figure S4A), mitotic B cells were at the CD43+/CD24+ (pre-B1) stage (Figure S4B), and mitotic erythroblasts were at the basophilic or polychromatic erythroblast stages (CD71 high or intermediate, Figure S4C). The extremely low abundance of mitotic LSK cells in haematopoietic tissue precluded their analysis in these experiments.

Having characterised the developmental status of mitotic cells in each lineage, we identified these rare cells within the lineage-purified precursor populations by immunofluorescence using an antibody against Histone $\mathrm{H} 3$ phosphorylated at serine 10 (pH3S10). Tagged condensin subunits were visualised using an anti-GFP nanobody. Fluorescence quantitation on prometaphase chromosomes confirmed that higher levels of both condensin I and II associate with chromatin in the $\mathrm{T}$ cell lineage compared to $\mathrm{B}$ cell or erythroid precursors (Figure 3A and 3B, Figure S5), in agreement with the flow cytometry data (Figure 2). This was further confirmed using a polyclonal antibody against Ncaph2 to probe cells from wild type mice, demonstrating that elevated condensin expression in T cells is not an artefact of the reporter tag (Figure S6).

The pattern of Ncaph localisation was broadly similar across haematopoietic cell lineages (Figure 3C, Figure S7A), yet distinct from patterns previously described in cultured human cell lines. For example, Ncaph is predominantly cytoplasmic during interphase in HeLa cells ${ }^{19,20}$, but localises within euchromatic subnuclear domains, characterised by low intensity DAPI staining, in interphase primary haematopoietic cells (Figure 3C-i, Figure S7A-i). During early mitosis, Ncaph relocalised to form foci proximal to regions of high DAPI intensity, presumably centromeric loci (Figure 3C-ii, Figure S7A-ii). By late prometaphase, dispersed Ncaph foci had coalesced with DAPI dense regions as centromeres aligned at the metaphase plate (Figure 3C-iii, Figure S7A-iii). We found anaphase cells to be extremely rare and challenging to identify from primary haematopoietic tissue; however, Ncaph fluorescence was visible on chromosome arms in the small number of cells identified (Figure 3C-iv, Figure S7A-iv, $\mathrm{n}=$ between 1 and 5 anaphase cells per cell type).

Ncaph2 localised similarly to Ncaph during interphase and early mitosis, transitioning from DAPI-poor regions to form centromeric foci (Figure 3D-i \& 3Dii, Figure S7B-i \& S7B-ii). However, relative to Ncaph, Ncaph2 was more clearly enriched along chromosome arms in late prometaphase cells (Figure 3D-iii, Figure S7B-iii), and remained on both centromeres and arms during anaphase (Figure 3D-iv). Thus, despite cell lineage-specific differences in the expression level of Ncaph and Ncaph2 (Figure 2, Figure 3A and 3B, Figure S5), their cell cycle distribution remains unchanged.

We next compared the chromosomal loading of topoisomerase IIa and Ki-67, two other known structural components of mitotic chromosomes, between cell types. Topoisomerase IIa, which cooperates with condensins to remove topological linkages between DNA molecules, localised most prominently to centromeric sequences, and was greatly enriched on prometaphase chromosomes in the thymic $\mathrm{T}$ cell lineage, as compared to mitotic $\mathrm{B}$ cell precursors (Figure S8A). The chromosome envelope protein Ki67 showed a similar cell-lineage-specific enrichment (Figure S8B). Other structural components of mitotic chromosomes therefore also reside at higher levels on chromatin in thymic $\mathrm{T}$ cell precursors, demonstrating that developmental changes to the protein content of mitotic chromosomes are not restricted to the two condensin complexes.

\section{Distinct condensin dynamics in live haematopoietic cells}

To better understand the dynamic behaviour of Ncaph and Ncaph2 in live haematopoietic precursors, we 
bioRxiv preprint doi: https://doi.org/10.1101/2020.11.04.367847; this version posted November 4, 2020. The copyright holder for this preprint (which was not certified by peer review) is the author/funder, who has granted bioRxiv a license to display the preprint in perpetuity. It is made available under aCC-BY-NC 4.0 International license.

used Fluorescence Correlation Spectroscopy (FCS). Due to the low incident light intensities used in FCS, it is a reasonably non-invasive method with single molecule sensitivity that allows the dynamic behaviour of fluorescent molecules (e.g., their molecular movement / diffusion) to be analysed in living cells at physiological concentrations ${ }^{39-44}$. In FCS, fluctuations in fluorescence intensity are recorded at high temporal resolution, and then used to infer the molecular movement of molecules entering or leaving a subfemtoliter detection volume (Figure 4A). Thus, fast or free-diffusing molecular movement can be reflected by autocorrelation curves that decay rapidly, whereas slow or bound molecules can result in FCS curves with longer decay times (Figure 4A, Methods).

We performed FCS to compare the molecular movement of mClover-tagged condensin subunits in freshly isolated thymocytes and bone marrow cells during short term $(<3$ hour) ex vivo culture. To validate the experimental pipeline, we first compared FCS measurements for Ncaph2-mClover between interphase and prometaphase thymocytes, when movement is expected to transition from fast to slow as condensin II engages with chromatin ${ }^{22}$. Measurements were performed at the points of highest fluorescence intensity (DAPI poor euchromatin during interphase, and centromeric chromatin in mitotic cells - Figure 4B). Autocorrelation curves indicated that Ncaph2 molecules exhibited lower mobility during mitosis relative to interphase (Figure $4 \mathrm{C}$ ), consistent with known patterns of chromosomal binding upon mitotic entry ${ }^{1}$. The same result was obtained using a mouse embryonic stem cell line stably expressing SMC2-mClover (Figure 4D). Next, we compared FCS measurements between prometaphase cells in short-term cultures of dissociated thymus versus bone marrow tissue. Because $>90 \%$ of mitotic cells in the bone marrow express the erythroid lineage marker Ter-119 (Figure S4D), and $>90 \%$ of mitotic cells in the thymus express the $\mathrm{T}$ cell lineage marker CD8+ (Figure S4E), this experiment primarily compared mitotic T cell precursors and mitotic erythroblasts. For both Ncaph and Ncaph2, lower mobility was evident in mitotic cells from the thymus relative to the bone marrow (Figure 4E).

To interpret these changes in molecular behaviour, autocorrelation curves were fitted with a twocomponent diffusion model with triplet correction (Methods). Lower average mobility of kleisins during mitosis in the $\mathrm{T}$ cell versus erythroid lineage could theoretically arise either from an increase in the relative proportion of slowly diffusing molecules (slow FCS component), or from lower molecular mobility (diffusion) of kleisin molecules within either component. Fitting identified a significantly higher fraction of slowly diffusing molecules in mitotic $\mathrm{T}$ cells compared to bone marrow cells (Figure 4F). In contrast, the decay times for the fast and slow components were not significantly different (Figure $4 \mathrm{G}$ and $4 \mathrm{H}$ ). Together, these data are consistent with Ncaph and Ncaph2 being, on average, less mobile during thymic $\mathrm{T}$ cell mitosis compared to erythroblast mitosis due to a larger proportion of molecules bound to chromatin, where they can potentially contribute to mitotic chromosome formation.

\section{Evidence that condensin activity differs between cell lineages}

Having demonstrated high levels of condensin expression and loading in thymic $\mathrm{T}$ cells, we next asked what purpose this serves during $\mathrm{T}$ cell mitosis. The mitotic genome occupied a significantly smaller volume in prometaphase $\mathrm{T}$ cell precursors relative to $\mathrm{B}$ cell or erythroid precursors (Figure $5 \mathrm{~A}$ and $5 \mathrm{~B}$ ). The degree of compaction during mitosis was not a function of overall cell size, because no significant differences were observed in the average size of $\mathrm{T}$ cell compared to B cell or erythroid precursor populations in G2 phase (Figure 5C). Nor did it reflect lineagespecific differences in the distribution of cells across mitotic subphases, because comparable results were obtained when cells were harvested 30 minutes following intra-peritoneal colcemid injection to enrich mitotic cells at prometaphase (Figure S9). Thus, the degree of prometaphase chromosome compaction correlates with the level of condensin loading during different haematopoietic cell divisions.

We also found evidence that high levels of condensin activity are a required property of thymic $\mathrm{T}$ cell divisions. We and others have previously reported that mice carrying a germline hypomorphic mutation in Ncaph2 (I15N) display a developmental block during $\mathrm{T}$ cell development ${ }^{27,8}$. This mutation reduces the level of Ncaph2 protein on mitotic chromosomes (Figures $5 \mathrm{D} \& 5 \mathrm{E})$, and impairs mitotic genome compaction (Figure 5F). To assess the effect of the I15N mutation on chromosome segregation we quantified the change in tetraploid cell frequency in each lineage (Figure $5 G)$. Tetraploidy was increased to a far greater extent in thymic $\mathrm{T}$ cells compared to $\mathrm{B}$ cell or erythroid precursors (Figure $5 \mathrm{H}$ ). The average $\gamma \mathrm{H} 2 \mathrm{AX}$ signal (a marker of DNA damage) was also elevated to a far greater extent in thymic T cells (Figure 5I and 5J). The increase in condensin activity in $\mathrm{T}$ cell precursors therefore manifests as hypercompacted 
bioRxiv preprint doi: https://doi.org/10.1101/2020.11.04.367847; this version posted November 4, 2020. The copyright holder for this preprint (which was not certified by peer review) is the author/funder, who has granted bioRxiv a license to display the preprint in perpetuity. It is made available under aCC-BY-NC 4.0 International license.

chromatin during prometaphase, and is required to maintain ploidy and avoid DNA damage at this stage of development.

\section{Non-SMC subunit levels regulate condensin holocomplex formation during development}

Each pentameric condensin complex is made up of two subcomplexes: one comprising the SMC2/4 heterodimer (8S), and the other comprising the kleisin and HEAT repeat subunits $\left(11 \mathrm{~S}\right.$, Figure $\left.6 \mathrm{~A},{ }^{13,45}\right)$. To determine whether other subunits of condensins I and II show differences in abundance concordant with Ncaph and Ncaph2 during blood development, we used immunoblotting to probe total protein extracts from $\mathrm{T}, \mathrm{B}$ and erythroid precursor cell populations purified from wild type mice (Figure 6B). Consistent with our findings in transgenic mice, this showed that wild type Ncaph and Ncaph2 were expressed at substantially higher levels in thymic $T$ cells compared to bone marrow B cells and erythroblasts. Ncapg and Ncapg2, HEAT repeat subunits of condensin I and II, respectively, showed a similar bias with substantially higher levels in thymic T cells (Figure 6B). In striking contrast, the levels of Smc 2 and Smc4 protein remained relatively constant across cell types (Figure 6B). This suggests that the stoichiometry of condensin subunits is regulated in a cell lineage-specific manner, and that a substantial fraction of Smc2 and Smc4 proteins does not associate with condensin holocomplexes in bone marrow B cells and erythroblasts.

To investigate this further, we performed immunoprecipitation (IP) of Smc4 from thymus and bone marrow whole cell protein extracts $(n=4)$, then identified interacting proteins by mass spectrometry and Label-Free Quantitation (LFQ). Eleven proteins were significantly enriched ( $\log 2$ Fold Change $>4, \mathrm{p}<$ 0.01 ) in Smc4 IPs compared to IgG control from thymic extract, including all 5 subunits of the condensin I holocomplex (Figure S10A). When the Smc4 IPs were conducted using bone marrow extract, seven proteins were enriched over IgG control including Smc2 and Smc4 but not Ncaph, Ncapg or Ncapd2 (Figure S10B).

Unexpectedly, no peptides from the condensin IIspecific subunits Ncaph2, Ncapg2 and Ncapd3 were identified in any IP performed using the antiSmc4 antibody. However, IP of Ncaph2 followed by immunoblotting for Smc4 revealed that Smc4 / kleisin interactions, and, therefore, presumably intact condensin II complexes, were indeed present in thymic tissue (Figure S10C). We conclude that failure to detect condensin II-specific subunits is likely due to a technical issue such as occlusion of the relevant Smc4 epitope by interactions with subunits of condensin II, but not condensin I.

Using the same mass spectrometry dataset, we next asked whether the fraction of Smc4 associated with other condensin I subunits differed between thymus and bone marrow protein extracts. Smc2 was recovered as efficiently as Smc4 in both tissues, supporting a stable 1:1 interaction between members of the $8 \mathrm{~S}$ subcomplex that does not differ significantly between these two haematopoietic tissues (Figures 6C and 6D). In the thymus, Ncapg, Ncapd2 and Ncaph were recovered at 6 to 10 -fold lower efficiency relative to $\mathrm{Smc} 2$ and 4 (Figure 6D). However, in the bone marrow samples, members of the $11 \mathrm{~S}$ subcomplex were recovered at 70 to 579 -fold lower efficiency than the Smc 4 bait. This suggests that a much larger fraction of the $8 \mathrm{~S}$ SMC heterodimer resides within pentameric condensin holocomplexes in thymic $\mathrm{T}$ cells relative to bone marrow cells (including $\mathrm{B}$ cell and erythroid precursors).

This finding was further corroborated by the fractionation of native protein complexes over a sucrose gradient followed by western blotting. We found that Ncapg and Smc4 co-sedimented across the same fractions in thymic protein extract (Figure 6E, top). However, Ncapg expression was below detectable levels in any fraction of bone marrow protein extract, and the sedimentation of Smc4 was shifted towards fractions containing protein assemblies of smaller size (Figure 6E, bottom). Altogether, these data demonstrate that cell types from the bone marrow, including both B cell and erythroid precursors, contain a large pool of $8 \mathrm{~S}$ SMC heterodimers that are not associated with subunits of the $11 \mathrm{~S}$ subcomplex. Substoichiometric expression of the $11 \mathrm{~S}$ subcomplex is therefore a developmental mechanism that controls the formation (Figure 6), and hence the activity (Figure 5), of condensin holocomplexes in different haematopoietc cell lineages.

\section{Discussion}

Condensins are conserved in all domains of life, and their role in restructuring chromosomes during mitosis is fundamental to genome propagation and inheritance. Given that the same genome needs to be restructured during each cell division in multicellular organisms, it has been assumed that the restructuring process remains unchanged during somatic development ${ }^{27,46}$. The data presented here challenge this assumption.

In this study we developed new transgenic mouse 
bioRxiv preprint doi: https://doi.org/10.1101/2020.11.04.367847; this version posted November 4, 2020. The copyright holder for this preprint (which was not certified by peer review) is the author/funder, who has granted bioRxiv a license to display the preprint in perpetuity. It is made available under aCC-BY-NC 4.0 International license.

models that enable quantitative analysis of limiting condensin subunits across different physiological cell divisions during mammalian tissue development. This enabled us to observe, for the first time, that different cell lineages express (Figure 2), load (Figures $3 \& 4$ ), and likely require (Figure 5), different amounts of condensin to compact and segregate their genome during mitosis. Relative to other cell types examined, thymic T cell divisions show unusually high levels of condensin loading (Figures 3 and 4, Figures S5 and S6), which results in hypercompacted mitotic chromatin (Figure 5A and B, Figure S9). Both mitotic chromosome compaction (Figure 5E) and ploidy maintenance (Figure 5G) are hypersensitive to a missense mutation in the condensin II subunit Ncaph2, which reduces the amount of protein on mitotic chromosomes (Figure 5D). The regulation of condensin dose therefore not only contributes to differences in the extent of mitotic chromosome compaction over different cell division cycles during development, but is also required for cell-lineage-specific chromosome segregation.

We found that the dose of condensin holocomplexes is kept low in bone marrow B cells and erythroblasts, by limiting expression of the $11 \mathrm{~S}$ subcomplex (Figure 6). Substoichiometric kleisin expression is known to restrict condensin complex assembly in HeLa cells ${ }^{23}$, and our data show that a related mechanism controls the number of condensin holocomplexes as cells adopt different developmental fates. Unexpectedly, we found that B cells and erythroblasts contain a substantial pool of SMC2/SMC4 heterodimer lacking kleisin and HEAT subunits (Figure 6). This heterodimer lacks subunits that are essential for efficient ATPase activity ${ }^{14,47}$ and therefore cannot promote chromosome condensation in the same manner as the holocomplex ${ }^{4}$, but could conceivably perform alternative functions ${ }^{48}$.

Current models of mitotic chromosome formation posit that condensins drive the formation of loops through a DNA-dependent motor function, while simultaneously anchoring these loops to a central protein scaffold. The frequency of condensin binding should therefore influence the number and size of loops. Recent in vitro experiments have linked increased condensin concentrations with the formation of specialised structures termed Z-loops, which form when condensin complexes traverse one another during loop extrusion, and are predicted to increase the overall level of genome compaction ${ }^{49,50}$. Changes in the overall number of loops, and their structural configuration, therefore provide a plausible mechanism through which increased condensin loading in $\mathrm{T}$ cells could increase the degree of chromosome compaction.
What specialised features of thymic $\mathrm{T}$ cell division might require elevated condensin activity? We discuss two broad possibilities: that condensin is required to prepare the genome for quiescence upon mitotic exit, or to process linkages between sister chromatids that have been carried forward from the preceding $S$ phase.

Preparing the genome for quiescence: Cell division in the thymus occurs most extensively at the transition from the CD4-CD8 $8^{-}$to the $\mathrm{CD} 4^{+} \mathrm{CD} 8^{+}$stage, when $\mathrm{T}$ cell precursors expressing successfully rearranged TCR $\beta$ genes undergo 5 or 6 rapid divisions before entering a quiescent state to complete rearrangement of the TCRa locus ${ }^{51}$. Given that cell numbers increase with each division during this proliferative burst, a large fraction of mitotic cells in the thymus should be in the terminal division cycle, preparing to enter quiescence. This transition is associated with the establishment of a highly compacted interphase genome structure and globally reduced transcription ${ }^{46}$. It was previously suggested that condensin II plays a key role in the establishment and maintenance of the compacted interphase genome at this stage of development ${ }^{46}$, and in other cell types entering quiescence ${ }^{52}$. The high level of condensin on chromosomes as cells enter quiescence supports this hypothesis, and raises the possibility that chromosome structure may be 'primed' towards the quiescent state during the preceding cell cycle.

\section{Promoting the removal of topological linkages:}

Mice with homozygous missense mutations in Ncaph2 I15N/I15N develop hypoplasia specifically in the thymus, despite the mutation being present in every cell lineage 27. We have shown that this occurs due to profound decatenation failure, tetraploidy and chromosome instability, which occurs in $\mathrm{T}$ cell but not $\mathrm{B}$ cell or erythroid precursors $^{8}$ (Figure $5 \mathrm{G}-\mathrm{J}$ ). Upon aging, Ncaph2 $2^{115 N / 115 \mathrm{~N}}$ mice develop thymic lymphomas which are drastically accelerated by concomitant tp 53 mutation ${ }^{8}$. Combined with the elevated expression (Figure 2) and binding (Figures $3 \& 4$ ) of non-SMC condensin subunits in T cells, as compared with other cells of similar size, this suggests that thymic $\mathrm{T}$ cell divisions require more condensin to decatenate their genome.

In one model, events during the $S$ phase of the preceding cell cycle could generate comparably higher numbers of linkages between sister chromatids, which require more condensins for efficient resolution during the $M$ phase. Such linkages could include precatenanes arising from replication fork rotation ${ }^{53-}$ 55. Consistent with this possibility, we also observed 
bioRxiv preprint doi: https://doi.org/10.1101/2020.11.04.367847; this version posted November 4, 2020. The copyright holder for this preprint (which was not certified by peer review) is the author/funder, who has granted bioRxiv a license to display the preprint in perpetuity. It is made available under aCC-BY-NC 4.0 International license.

substantial enrichment of topoisomerase IIa on $\mathrm{T}$ cell chromosomes (Figure S8A). Chromatid linkages can also arise at sites where under-replicated DNA is carried forward into mitosis ${ }^{56}$. These linkages can be resolved via the Mitotic DNA synthesis (MiDAS) pathway ${ }^{57,58}$, which is triggered by condensin-driven changes in chromosome topology during prophase ${ }^{57}$. We speculate that a higher number of condensin complexes on mitotic chromosomes could enhance the efficiency of this process.

Looking beyond condensins, it is notable that lymphomas which originate from thymic $\mathrm{T}$ cell blasts are the most common form of spontaneous tumour to arise in several mouse models with germline mutations in genome stability pathways, including TP53, ATM, Fancd2/Aldh2, Brca1 and Brca2 ${ }^{59-63}$. This suggests an inherent vulnerability to endogenous genome instability during these divisions, which is not due to aberrant VDJ recombination ${ }^{27,64,65}$. Many human genome instability syndromes are associated with developmental abnormalities and cancer predispositions that affect particular organs ${ }^{66}$. A better understanding of endogenous sources of genome instability across cell lineages, and how the cell cydle has adapted to counter them, will therefore shed light on tissue-specific human disease pathology.

\section{Acknowledgements}

We thank Aude Fahrer for providing Ncaph2 $2^{115 N / 115 N}$ mice, the University of Edinburgh Transgenic Facility for performing CRISPR microinjections, the Biological Research Facility at the Western General Hospital for animal husbandry, the IGMM Flow Cytometry Facility, IGMM Advanced Imaging Resource, IGMM Mass Spectrometry facility, and Jack Stoddart for technical support. We are grateful to Javier Caceres, Wendy Bickmore and Carol-Anne Martin for comments on the manuscript. This work was supported by a Sir Henry Dale Fellowship from the Wellcome Trust (AW $102560 / Z / 13 / Z$ ) and an MRC Unit award to the MRC Human Genetics Unit.

\section{Author Contributions}

L.M. generated and validated transgenic mice and performed Flow Cytometry experiments in Figures 2 and S3 with help from A.W. D.P. performed and analysed FCS experiments with help from L.M. and I.C. J.W. performed Mass Spectrometry and analysed the data with help from GT. G.T. performed Immunofluorescence with help from L.S. and M.B. All other experiments were performed by G.T. A.W. conceived and supervised the study and wrote the paper with input from G.T., L.M. and D.P.

\section{Figure Legends}

\section{Figure 1: Generation of Ncaph and Ncaph2 reporter mouse models.}

A. Schematic diagrams showing the subunits of condensin I and II complexes. The kleisin subunits of condensin I and II are Ncaph and Ncaph2, respectively. B. CRISPR-Cas9 strategy for integrating mClover cassettes at the Ncaph and Ncaph2 loci using long single stranded deoxyoligonucleotides (ssODN) to generate Ncaphtg and Ncaph2tg alleles. Full details and sequences for the integrated cassettes are given in Appendix 1. C. Western blots prepared from thymic whole cell protein extract were probed with antibodies recognising endogenous Ncaph and Ncaph2. '+' indicates wildtype allele 'tg' indicates transgenic. D. Observed and expected genotype frequencies among 28 day-old animals generated from heterozygous crosses for each transgene. Chi-squared tests revealed no significant deviation from expected mendelian frequencies. E. Immunofluorescence imaging of mitotic murine embryonic fibroblast lines derived from Ncaphtg/tg and Ncaph2tg/tg embryos. Scale bar $=5 \mu \mathrm{m} \mathbf{F}$. Litter sizes from matings between animals heterozygous versus homozygous for Ncaphtg (top) and Ncaph2tg (bottom) reporter transgenes. ${ }^{*}$ indicates significant difference at $\mathrm{p}<1 \times 10-3$ from unpaired two-tailed t-tests $\mathbf{G}$. Weight of pups at 28 days postpartum. $\mathrm{M}=$ male, $\mathrm{F}=$ female, ${ }^{* *}$ indicates significant differences between genotypes $(\mathrm{M}+\mathrm{F}$ combined) at $\mathrm{p}<$ $1 \times 10-4$ (one-way ANOVA with Tukey's HSD posthoc test).

\section{Figure 2: Dynamic condensin expression levels during haematopoietic differentiation}

A. Diagram showing the generic flow cytometry workflow used to quantify reporter transgene expression in specific cell lineages, at specific cell cycle phases. mClover expression in panels $\mathrm{B}-\mathrm{D}$ was calculated specifically from cells in S/G2/M. Full gating details are shown in Figure S2. B \& C. Mean mClover fluorescence from different haematopoietic populations of Ncaph (B) and Ncaph2 (C) transgenic animals. Each data point represents the mean background-corrected mClover fluorescence for at least 400 (LSK) or 3000 (pre-B, pre-E, pre-T) cells from each of $n=5$ (LSK) or 6 (pre-B, pre-E, pre-T) animals collected over two independent experiments. D. The ratio of Ncaph to Ncaph2 expression in each cell population shown in panels B \& C. ${ }^{*}$ indicates significant differences at $\mathrm{p}<0.05,{ }^{* *}$ at $\mathrm{p}<1 \times 10-3$, ${ }^{* *}$ 
bioRxiv preprint doi: https://doi.org/10.1101/2020.11.04.367847; this version posted November 4, 2020. The copyright holder for this preprint (which was not certified by peer review) is the author/funder, who has granted bioRxiv a license to display the preprint in perpetuity. It is made available under aCC-BY-NC 4.0 International license.

at $\mathrm{p}<1 \times 10-6$ (one-way ANOVA with Tukey's HSD from a mouse embryonic stem cell line with mClover posthoc test).

\section{Figure 3: Condensin expression and localisation during haematopoietic mitoses}

A \& B Quantitation of Ncaph (A) and Ncaph2 (B) signal colocalised with chromosomes of cells in late prometaphase / metaphase. Cells were magnetically purified from bone marrow (B220+ pre-B cells, Ter119+ Erythroid (pre-E) cells) and thymus (CD8+ pre-T cells). The developmental status of mitotic cells within each lineage is shown in Figure S4A, S4B and S4C. DAPI signal was used to segment mitotic chromosomes in 3D, and total kleisin fluorescence (mClover fluorescence plus GFP nanobooster) was quantified specifically within this volume. indicates significant differences between groups at $\mathrm{p}<0.05$, ${ }^{* *}$ indicates $\mathrm{p}<1 \times 10-7$ from one-way ANOVA with Tukey's HSD posthoc test. Data are from a single experiment. C \& D. Representative immunofluorescence images of pre-T cells (CD8+) during interphase and different mitotic subphases (i) to iv) from Ncaphtg/tg (C) and Ncaph2tg/tg (D) animals. Representative images from pre-B and pre-E cells are shown in Figure S5. Signal from the mClover/488 channel was adjusted in this image series to enable kleisin localisation to be visualised across diverse expression levels. For comparison, images from the same cells without signal adjustment are shown in Figure S7. Images show single z-planes, scale bar 3 $\mu \mathrm{m}$. A large majority of $\mathrm{pH} 3 \mathrm{~S} 10$ positive cells was in early or late prometaphase (images representative of $>30$ cells per lineage). Anaphase cells were extremely rare (images representative of 1 to 5 cells per lineage).

\section{Figure 4: Tissue-specific mobility of Ncaph and Ncaph2 during mitosis}

A. Schematic illustrating the use of Fluorescence Correlation Spectroscopy (FCS) in these experiments. Grey ellipse represents the detection volume. See Methods for further details. B. Single z-plane images show representative measurement points from interphase and mitotic cells. Green 'x's indicate the representative regions where measurements were performed. Scale bar $=2 \mu \mathrm{m}$ C. Autocorrelation curves normalised to the same amplitude $(G(\tau)=1$ at the zeroth lag time) show a shift of the FCS curve, recorded at mitosis in thymocytes, towards longer characteristic decay times for Ncaph2-mClover relative to interphase, indicating more or longer-lasting interactions of Ncaph2-mClover with DNA. In panels $\mathrm{C}$ to $\mathrm{F}, \mathrm{n}$ indicates the number of FCS measurements used to generate curves, with each measurement from a different cell. D. As for panel C, with measurements homozygously fused to Smc2. For panels E - I, NcaphmClover is shown in the upper and Ncaph2-mClover in the lower position. E. Autocorrelation curves show slower mobility in mitotic thymocytes compared to bone marrow cells. Data were pooled from two independent experiments. F. Box and stripplots show the fraction of the slow component after fitting with a two-component diffusion model (Methods). Asterisks indicate statistically significant difference at $\mathrm{p}<0.01$ from two-tailed unpaired t-tests. $\mathbf{G} \& \mathbf{H}$. Boxplots show the characteristic decay times ( $\tau_{-}$D 1 and $\tau_{-}$ D2) of the FCS measurements obtained after fitting. Differences were not significant at $p<0.05$ in 2-tailed unpaired t-tests.

\section{Figure 5. Evidence that condensin activity differs} between cell lineages

A. Representative images of late prometaphase / metaphase bone marrow $\mathrm{B}$ cells (B220+ pre-B), bone marrow erythroid precursors (Ter119+ pre-E), and thymic T cells (CD8+ pre-T) from wildtype mice. Gells were purified and stained as described in Figure 3. Late prometaphase / metaphase cells were identified based on alignment of DAPI-dense centromeric regions. Scale bar $3 \mu \mathrm{m}$ B. DNA volume was measured following segmentation of DAPI stained chromosomes of cells represented in panel A. ${ }^{*}$ indicates $\mathrm{p}<0.02,{ }^{* *}$ indicates $\mathrm{p}<0.01$ from one-way ANOVA with Tukey's HSD posthoc test. C. Single cells were gated on lineage markers as depicted in Figure 2A, then G2 cells were gated as shown in the left panel (4N DNA content, phosphoH3 negative). Mean Forward Scatter (FSC) values from $>1000$ G2 cells per replicate ( $n=3$ from independent experiments) are shown on the right. Differences between groups were not significant at $\mathrm{p}$ $<0.05$ in a one-way ANOVA. D. Immunofluorescence images of mitotic thymocytes from wildtype and Ncaph $2^{115 \mathrm{~N} / 115 \mathrm{~N}}$ mice. DAPI signal was used to segment mitotic chromatin in 3 dimensions. Scale bar $3 \mu \mathrm{m}$ E. Quantification of Ncaph2 fluorescence within DAPI stained regions of prometaphase cells as shown in panel D. ${ }^{*}$ indicates significant difference at $\mathrm{p}<1$ $x$ 10-3 from two-tailed t-test. F. DNA volume was measured following segmentation of DAPI stained chromosomes of cells represented in panels D \& E. * indicates significant difference at $\mathrm{p}<5 \times 10-3$ from two-tailed t-test. G. The percentage of cells with $4 \mathrm{~N}$ or greater DNA content (a proxy for tetraploidy) was calculated as shown. At least 100,000 cells were analysed per sample $\mathbf{H}$. The fold increase in \% tetraploidy in different cell types homozygous versus heterozygous for the Ncaph2I15N mutation. I. Gating of $S$ phase cells for flow cytometric quantification of 
bioRxiv preprint doi: https://doi.org/10.1101/2020.11.04.367847; this version posted November 4, 2020. The copyright holder for this preprint (which was not certified by peer review) is the author/funder, who has granted bioRxiv a license to display the preprint in perpetuity. It is made available under aCC-BY-NC 4.0 International license.

$\gamma \mathrm{H} 2 \mathrm{Ax}$. J. Mean $\gamma \mathrm{H} 2 \mathrm{Ax}$ signal was calculated from $>1000 \mathrm{~S}$ phase cells in B cell (B220+ pre-B) Erythroid (Ter119+ pre-E) and $\mathrm{T}$ cell (total thymocyte, pre-T) precursors. The fold increase in mean $\gamma \mathrm{H} 2 \mathrm{Ax}$ signal in different cell types homozygous versus heterozygous for the Ncaph2I15N mutation is shown. For panels $\mathrm{H}$ $\& \mathrm{~J},{ }^{*}$ indicates significant difference at $\mathrm{p}<2 \times 10-3$, ${ }^{* *}$ at $\mathrm{p}<1 \times 10-3$, from one-way ANOVA with Tukey's HSD posthoc test.

Figure 6: The availability of non-SMC subunits controls the formation of condensin holocomplexes during tissue homeostasis

A. Schematic showing subunit composition of the $8 \mathrm{~S}$ and $11 \mathrm{~S}$ subcomplexes of condensin I (c I) and II (c II). B. Western blots from whole cell extract of wildtype thymocytes (pre-T), MACS-purified bone marrow B cells (B220+; pre-B) and erythroid cells (Ter-119+; pre-E) probed with polyclonal antibodies against condensin subunits. Common loading controls (Gapdh, actb, histone H3) showed consistently more diverse expression than Smc2 across cell types, and are therefore not shown. $\mathbf{C} \& \mathbf{D}$. Relative enrichment of condensin I subunits following Smc4 IP from thymus and bone marrow whole cell extract $(n=4$ samples from different animals, processed in parallel, per condition). The mean background-corrected Label Free Quantification (LFQ) Signal of the SMC4 bait was assigned the value of 1 , then equivalent values for other subunits were expressed relative to this. Data are presented in histogram (C) and table (D) format. Error bars indicate standard deviation $(\mathrm{n}=4) \mathbf{E}$. Western blots generated from thymus (top) and bone marrow (bottom) whole cell extract fractionated by sucrose gradient centrifugation, then probed with antibodies against Smc4 and Ncapg. The lower band (Ncapg) was not detected in the bone marrow sample.

Figure S1: Thymic $T$ cell development is not perturbed in condensin reporter mice.

A. Dotplots show the distribution of T cell precursor subsets in thymus from wildtype, Ncaph and Ncaph2 reporter transgenic, and Ncaph $2^{115 \mathrm{~N} / 115 \mathrm{~N}}$ mice. Mean and standard deviation from $\mathrm{n}=3$ animals from a single experiment are shown below the plots. B. Absolute numbers of precursor subsets from the experiment shown in panel B. ${ }^{*}$ indicates significant differences at $\mathrm{p}<0.01$ from one-way ANOVA with Tukey's HSD test.

\section{Figure S2: Flow cytometry gating strategies}

Identification of LSK cells (A), pre-B cells (B), pre-E cells $(\mathbf{C})$ and pre-T cells (D) by flow cytometry for Figures 2, Figure 5C, 5G \& 5H \& Figure S3. Lineage markers were not required to identify thymic $\mathrm{T}$ cells because $\mathrm{T}$ cells make up $>98 \%$ of total thymocytes.

Figure S3: T cells express higher levels of Ncaph and Ncaph2 throughout the S/G2/M phases

Cells were pre-gated as shown in Figure S2, then assigned to early $S$ phase, mid $S$ phase, late $S$ phase, or G2/M based on their DNA content. Mean mClover fluorescence was calculated for Ncaph (A) or Ncaph2 (B) from at least 1000 cells per data point, and background fluorescence was subtracted. $\mathrm{n}=6$ biological replicates from two independent experiments per condition. LSK cells were not analysed as they were present at numbers insufficient to obtain sufficient data for each cell cycle sub-phase. ${ }^{*}$ indicates significant differences between conditions at $\mathrm{p}<1 \mathrm{x}$ $10-6,{ }^{* *}$ at $\mathrm{p}<1 \times 10-7$, from one-way ANOVA with Tukey's HSD posthoc test.

Figure S4: Developmental staging of mitotic cells within haematopoietic tissue

Immunophenotyping of mitotic cells. Each population was stained with antibodies against cell surface developmental markers and the intracellular mitotic marker pH3S10. (A-C) the developmental distribution of mitotic cells within the pre- $\mathrm{T}$ (thymocyte, A), pre-B (B220+, B), and pre-E (Ter119+, C) cell populations. The expression of developmental markers on $\mathrm{pH} 3 \mathrm{~S} 10+$ mitotic cells is shown in blue, relative to all cells in red. D. $96.3 \%$ of $\mathrm{pH} 3 \mathrm{~S} 10+$ cells express the erythroid marker Ter119. E. $92.9 \%$ of mitotic thymocytes express the T cell marker CD8. Percentages and standard deviations in panels $\mathrm{D}$ and $\mathrm{E}$ are from $\mathrm{n}=3$ mice.

Figure S5: Ncaph and Ncaph2 are enriched on mitotic chromatin in pre-T cells compared to pre-E and pre-B cells

Images show maximum intensity projections from the same cells represented in Figures 3 and S7, with DAPI and mClover channels shown separately. To enable comparison of mClover intensity between cell types, signal intensity was adjusted for optimal visualisation in the pre- $\mathrm{T}$ cell late prometaphase / metaphase condition, and then images of other cell types and mitotic subphases were processed in an identical manner. A. Ncaph-mClover ${ }^{\mathrm{tg} / \mathrm{tg}}$ B. Ncaph2-mClovert ${ }^{\mathrm{g} /}$ tg. Scale bar $=3 \mu \mathrm{m}$.

Figure S6: Elevated Ncaph2 protein on $T$ cell mitotic chromosomes from non-transgenic animals

A. Images of prometaphase cells from wildtype mice probed with antibodies against $\mathrm{Ncaph} 2$ and $\mathrm{pH} 3 \mathrm{~S} 10$ and stained with DAPI. DAPI fluorescence was used to segment mitotic chromatin in 3D. Erythroid cells were not measured in this experiment. Scale bar $=3$ $\mu \mathrm{m}$ B. Quantification of Ncaph2 fluorescence within DAPI stained regions of prometaphase cells. ${ }^{*}$ indicates 
significant difference at $\mathrm{p}<1 \times 10^{-9}$ from an unpaired two-tailed t-test.

\section{Figure S7: Condensin localisation during haematopoietic mitoses.}

Representative immunofluorescence images of pre-B $\left(\mathrm{B} 220^{+}\right)$and pre-E (Ter-119+) cells during interphase and different mitotic subphases (i) to iv) from Ncapht ${ }^{\mathrm{g} /}$ tg (A) and Ncaph2 ${ }^{\text {tg/tg }}($ B) animals. Representative images from pre-T cells are shown in Figure 3. Signal from the mClover/488 channel was adjusted in these images to enable kleisin localisation to be visualised across diverse expression levels. For comparison, maximum-intensity projection images from the same cells without signal adjustment are shown in Figure S5. Images show single z-planes, scale bar $3 \mu \mathrm{m}$. A large majority of $\mathrm{pH} 3 \mathrm{~S} 10$ positive cells was in early or late prometaphase (images representative of $>30$ cells per condition). Anaphase cells were extremely rare (images representative of 1 to 5 cells per condition).

Figure S8: Quantification of TOP2A and Ki67 on prometaphase lymphocyte precursors

Immunofluorescence images of prometaphase pre-B and pre-T cells from wildtype mice probed with antibodies against Top $2 \alpha(\mathbf{A})$ or Ki67 (C) and pH3S10 (both). Erythroid cells were not studied in this experiment. Scale bar $=3 \mu \mathrm{m}$. B \& D. Quantification of immunofluorescence signal on mitotic chromatin. * indicates significant difference at $\mathrm{p}<1 \times 10^{-9}{ }^{* *}$ at $\mathrm{p}<$ $1 \times 10^{-10}$, from two-tailed unpaired t-tests.

Figure S9: Hypercompaction of mitotic chromatin in thymic $\mathbf{T}$ cells following colcemid exposure in vivo

A. Images of prometaphase cells from B cell (pre-B; B220+), Erythroid (pre-E; Ter119+) and T cell (pre-T; $\mathrm{CD} 8+$ ) populations magnetically purified from bone marrow and thymus of wildtype mice. Cells were attached to slides using cytospin, in contrast to Figure 3 where cells were allowed to settle on coverslips. Colcemid solution was injected into the intraperitoneal cavity 30 minutes before euthanasia and tissue harvest. Scale bar $=3 \mu \mathrm{m}$ B. Prometaphase DNA volume measured by segmentation of DAPI fluorescence in cell populations shown in panel A. * indicates significant differences between conditions at $\mathrm{p}<1 \times 10^{-6}$, ** at $\mathrm{p}<1 \times 10^{-7}$, from one-way ANOVA with Tukey's HSD posthoc test.

Figure S10 Tissue-specific interaction of $11 \mathrm{~S}$
A. Table listing all proteins significantly enriched $\left(p<0.01, \log _{2}\right.$ FC $\left.>4\right)$ following anti-SMC4 immunoprecipitation from thymic whole cell extract relative to IgG control. Protein enrichment was determined by Mass Spectrometry followed by LabelFreeQuantification. For comparison, $\log _{2}$ Fold Change (FC) and p-values from Bayes-moderated t-tests ${ }^{67}$ are shown for equivalent experiments from bone marrow whole cell extract. B. Proteins significantly enriched following immunoprecipitation of SMC4 from bone marrow whole cell extract, as described for panel A. Whether proteins that are not known members of the condensin complex are bona fide interactors was not a focus of the current study, and will require validation using independent methods. C. Western blot showing Ncaph2 immunoprecipitation from thymic whole cell extract, probed with an anti-Smc4 antibody. 


\section{References} perpetuity. It is made available under aCC-BY-NC 4.0 International license.

1. Ono, T. et al. Differential Contributions of Condensin I and Condensin II to Mitotic Chromosome Architecture in Vertebrate Cells. Cell 115, 109-121 (2003).

2. Uemura, T. et al. DNA topoisomerase II is required for condensation and separation of mitotic chromosomes in S. pombe. Cell 50, 917-925 (1987).

3. Gibcus, J. H. et al. A pathway for mitotic chromosome formation. Science 359, eaao6135 (2018).

4. Ganji, M. et al. Real-time imaging of DNA loop extrusion by condensin. Science eaar7831 (2018). doi:10.1126/science.aar7831

5. Liang, Z. et al. Chromosomes Progress to Metaphase in Multiple Discrete Steps via Global Compaction/Expansion Cycles. Cell 161, 11241137 (2015).

6. Umbreit, N. T. et al. Mechanisms generating cancer genome complexity from a single cell division error. Science 368, (2020).

7. Leiserson, M. D. M. et al. Pan-cancer network analysis identifies combinations of rare somatic mutations across pathways and protein complexes. Nat Genet (2014). doi:10.1038/ng.3168

8. Woodward, J. et al. Condensin II mutation causes T-cell lymphoma through tissue-specific genome instability. Genes \& Development 30, 2173-2186 (2016).

9. Terakawa, T. et al. The condensin complex is a mechanochemical motor that translocates along DNA. Science (2017). doi:10.1126/science.aan6516

10. Hirano, T. Condensin-Based Chromosome Organization from Bacteria to Vertebrates. Cell 164, 847-857 (2016).

11. Baxter, J. et al. Positive Supercoiling of Mitotic DNA Drives Decatenation by Topoisomerase II in Eukaryotes. Science 331, 1328-1332 (2011).

12. Charbin, A., Bouchoux, C. \& Uhlmann, F. Condensin aids sister chromatid decatenation by topoisomerase II. Nucleic Acids Research 42, 340348 (2013).

13. Hirano, T., Kobayashi, R. \& Hirano, M. Condensins, chromosome condensation protein complexes containing XCAP-C, XCAP-E and a Xenopus homolog of the Drosophila Barren protein. Cell 89, 511-521 (1997).
14. Piazza, I. et al. Association of condensin with chromosomes depends on DNA binding by its HEAT-repeat subunits. Nat Struct Mol Biol 21, 560-568 (2014).

15. Arumugam, P., Nishino, T., Haering, C. H., Gruber, S. \& Nasmyth, K. Cohesin's ATPase activity is stimulated by the C-terminal WingedHelix domain of its kleisin subunit. Curr. Biol. 16, 1998-2008 (2006).

16. Kimura, K. \& Hirano, T. ATP-Dependent Positive Supercoiling of DNA by $13 S$ Condensin: A Biochemical Implication for Chromosome Condensation. Cell 90, 625-634 (1997).

17. Elbatsh, A.M.O. etal. Distinct Roles for Condensin's Two ATPase Sites in Chromosome Condensation. Molecular Cell 76, 724-737.e5 (2019).

18. Kschonsak, M. et al. Structural Basis for a SafetyBelt Mechanism. That Anchors Condensin to Chromosomes, Cell 171, 588-600.e24 (2017).

19. Ono, T., Fang, Y., Spector, D. L. \& Hirano, T. Spatial and Temporal Regulation of Condensins I and II in Mitotic Chromosome Assembly in Human Cells. Mol. Biol. Cell 15, 3296-3308 (2004).

20. Hirota, T., Gerlich, D., Koch, B., Ellenberg, J. \& Peters, J.-M. Distinct functions of condensin I and II in mitotic chromosome assembly. Journal of Cell Science 117, 6435-6445 (2004).

21. Ono, T., Yamashita, D. \& Hirano, T. Condensin II initiates sister chromatid resolution during $\mathrm{S}$ phase. The Journal of Cell Biology 200, 429-441 (2013).

22. Gerlich, D., Hirota, T., Koch, B., Peters, J.-M. \& Ellenberg, J. Condensin I stabilizes chromosomes mechanically through a dynamic interaction in live cells. Curr. Biol. 16, 333-344 (2006).

23. Walther, N. et al. A quantitative map of human Condensins provides new insights into mitotic chromosome architecture. The Journal of Cell Biology jcb.201801048 (2018). doi:10.1083/ jcb.201801048

24. Shintomi, K. \& Hirano, T. The relative ratio of condensin I to II determines chromosome shapes. Genes \& Development 25, 1464-1469 (2011).

25. Martin, C.-A. et al. Mutations in genes encoding condensin complex proteins cause microcephaly through decatenation failure at mitosis. Genes \& Development 30, 2158-2172 (2016).

26. Khan, T. N. et al. Mutations in NCAPG2 Cause a Severe Neurodevelopmental Syndrome 
bioRxiv preprint doi: https://doi.org/10.1101/2020.11.04.367847; this version posted November 4, 2020. The copyright holder for this preprint (which was not certified by peer review) is the author/funder, who has granted bioRxiv a license to display the preprint in perpetuity. It is made available under aCC-BY-NC 4.0 International license.

that Expands the Phenotypic Spectrum of Condensinopathies. Am. J. Hum. Genet. 104, 94111 (2019).

27. Gosling, K. M. et al. A mutation in a chromosome condensin II subunit, kleisin $\beta$, specifically disrupts T cell development. Proceedings of the National Academy of Sciences 104, 12445-12450 (2007).

28. Micheli, G., Luzzatto, A. R., Carrì, M. T., de Capoa, A. \& Pelliccia, F. Chromosome length and DNA loop size during early embryonic development of Xenopus laevis. Chromosoma 102, 478-483 (1993).

29. Ladouceur,A.-M.etal.CENP-A and topoisomeraseII antagonistically affect chromosome length. The Journal of Cell Biology 216, 2645-2655 (2017).

30. Hagstrom, K. A. C. elegans condensin promotes mitotic chromosome architecture, centromere organization, and sister chromatid segregation during mitosis and meiosis. Genes \& Development 16, 729-742 (2002).

31. Kieserman, E. K. \& Heald, R. Mitotic chromosome size scaling in Xenopus. Cell Cycle 10, 3863-3870 (2011).

32. Belmont, A. S., Sedat, J. W. \& Agard,D. A. A threedimensional approach to mitotic chromosome structure: evidence for a complex hierarchical organization. The Journal of Cell Biology 105, 7792 (1987).

33. Hyman, A. H. \& Simons, K. The new cell biology: Beyond HeLa cells. Nature 480, 34 (2011).

34. Nishide, K. \& Hirano, T. Overlapping and Nonoverlapping Functions of Condensins I and II in Neural Stem Cell Divisions. PLoS Genet 10, e1004847 (2014).

35. Houlard, M. et al. Condensin confers the longitudinal rigidity of chromosomes. Nat Cell Biol 17, 771-781 (2015).

36. Miura, H., Quadros, R. M., Gurumurthy, C. B. \& Ohtsuka, M. Easi-CRISPR for creating knock-in and conditional knockout mouse models using long ssDNA donors. Nat Protoc 13, 195-215 (2018).

37. Samejima, K. et al. Functional analysis after rapid degradation of condensins and 3D-EM reveals chromatin volume is uncoupled from chromosome architecture in mitosis. Journal of Cell Science 131, jcs210187 (2018).

38. Hirano, T. Condensins: universal organizers of chromosomes with diverse functions. Genes \& Development 26, 1659-1678 (2012).
39. Giri, R. et al. Ordered patterning of the sensory system is susceptible to stochastic features of gene expression. eLife 9, (2020).

40. Maharana, S. et al. RNA buffers the phase separation behavior of prion-like RNA binding proteins. Science 360, 918-921 (2018).

41. Papadopoulos, D. K. et al. Control of Hox transcription factor concentration and cell-tocell variability by an auto-regulatory switch. Development dev.168179 (2019). doi:10.1242/ dev.168179

42. Skouloudaki, K. et al. Yorkie controls tube length and apical barrier integrity during airway development. The Journal of Cell Biology 218, 2762-2781 (2019).

43. Vukojevic, V., Papadopoulos, D. K., Terenius, L., Gehring, W. J. \& Rigler, R. Quantitative study of synthetic Hox transcription factor-DNA interactions in live cells. Proc. Natl. Acad. Sci. U.S.A. 107,4093-4098 (2010).

44. Vukojević, V. et al. Study of molecular events in cells by fluorescence correlation spectroscopy. Cell. Mol. Life Sci. 62, 535-550 (2005).

45. Kimura, K. \& Hirano, T. Dual roles of the $11 \mathrm{~S}$ regulatory subcomplex in condensin functions. Proceedings of the National Academy of Sciences 97, 11972-11977 (2000).

46. Rawlings, J. S., Gatzka, M., Thomas, P. G. \& Ihle, J. N. Chromatin condensation via the condensin II complex is required for peripheral T-cell quiescence. The EMBO Journal 30, 263-276 (2010).

47. Hassler, M. et al. Structural Basis of an Asymmetric Condensin ATPase Cycle. Molecular Cell 74, 1175-1188.e9 (2019).

48. Sakai, A., Hizume, K., Sutani, T., Takeyasu, K. \& Yanagida, M. Condensin but not cohesin SMC heterodimer induces DNA reannealing through protein-protein assembly. The EMBO Journal 22, 2764-2775 (2003).

49. Kim, E., Kerssemakers, J., Shaltiel, I. A., Haering, C. H. \& Dekker, C. DNA-loop extruding condensin complexes can traverse one another. Nature 579, 438-442 (2020).

50. Banigan, E. J., van den Berg, A. A., Brandão, H. B., Marko, J. F. \& Mirny, L. A. Chromosome organization by one-sided and two-sided loop extrusion. eLife 9, (2020). 
bioRxiv preprint doi: https://doi.org/10.1101/2020.11.04.367847; this version posted November 4, 2020. The copyright holder for this preprint (which was not certified by peer review) is the author/funder, who has granted bioRxiv a license to display the preprint in

51. Kreslavsky, T. et al. $\beta$-Selection-Induced Proliferation Is Required for $\alpha \beta \mathrm{T}$ Cell Differentiation. Immunity 37, 840-853 (2012).

52. Swygert, S. G. et al. Condensin-Dependent Chromatin Compaction Represses Transcription Globally during Quiescence. Molecular Cell (2018). doi:10.1016/j.molcel.2018.11.020

53. Sundin, O. \& Varshavsky, A. Terminal stages of SV40 DNA replication proceed via multiply intertwined catenated dimers. Cell 21, 103-114 (1980).

54. Champoux, J. J., McCoubrey, W. K. \& Been, M. D. DNA structural features that lead to strand breakage by eukaryotic type-I topoisomerase. Cold Spring Harb Symp Quant Biol 49, 435-442 (1984).

55. Postow, L., Crisona, N. J., Peter, B. J., Hardy, C. D. \& Cozzarelli, N. R. Topological challenges to DNA replication: conformations at the fork. Proceedings of the National Academy of Sciences 98, 82198226 (2001).

56. Fragkos, M. \& Naim, V. Rescue from replication stress during mitosis. Cell Cycle 16, 613-633 (2017).

57. Minocherhomji, S. et al. Replication stress activates DNA repair synthesis ingmitosis. Nature 528, 286290 (2015).

58. Bhowmick, R., Minocherhomji, S. \& Hickson, I. D. RAD52 Facilitates Mitotic DNA Synthesis Following Replication Stress. Molecular Cell 64, 1117-1126 (2016).

59. Donehower, L. A. et al. Mice deficient for p53 are developmentally normal but susceptible to spontaneous tumours. , Published online: 19 March 1992; | doi:10.1038/356215a0 356, 215-221 (1992).

60. Friedman, L. S. et al. Thymic lymphomas in mice with a truncating mutation in Brca2. Cancer Research 58, 1338-1343 (1998).

61. Langevin, F., Crossan, G. P., Rosado, I. V., Arends, M. J. \& Patel, K. J. Fancd 2 counteracts the toxic effects of naturally produced aldehydes in mice. Nature 475, 53-58 (2011).

62. Ludwig, T., Fisher, P., Ganesan, S. \& Efstratiadis, A. Tumorigenesis in mice carrying a truncating Brcal mutation. Genes \& Development 15, 1188-1193 (2001).

63. Xu, Y. et al. Targeted disruption of ATM leads to growth retardation, chromosomal fragmentation during meiosis, immune defects, and thymic lymphoma. Genes \& Development 10, 2411-2422 (1996).

64. Nacht, M. \& Jacks, T. V(D)J recombination is not required for the development of lymphoma in p53-deficient mice. Cell Growth Differ. 9, 131-138 (1998).

65. Petiniot, L. K. et al. RAG-mediated V(D)J recombination is not essential for tumorigenesis in Atm-deficient mice. Molecular and Cellular Biology 22, 3174-3177 (2002).

66. Taylor, A. M. R. et al. Chromosome instability syndromes. Nat Rev Dis Primers 5, 1-20 (2019).

67. Kammers, K., Cole, R. N., Tiengwe, C. \& Ruczinski, I. Detecting Significant Changes in Protein Abundance. EuPA Open Proteom 7, 11-19 (2015). 
bioRxiv preprint doi: https://doi.org/10.1101/2020.11.04.367847; this version posted November 4, 2020. The copyright holder for this preprint (which was not certified by peer review) is the author/funder, who has granted bioRxiv a license to display the preprint in perpetuity. It is made available under aCC-BY-NC 4.0 International license.

\title{
Developmental regulation of mitotic chromosome formation revealed by condensin reporter mice
}

\author{
Taylor et al
}

\section{Materials and Methods}

\section{Mouse maintenance and husbandry}

All animal work was approved by a University of Edinburgh internal ethics committee and was performed in accordance with institutional guidelines under license by the UK Home Office (PPL 60/4424, PPL P16EFF7EE). Mice were maintained at the Biological Research Facility, Western General Hospital. All transgenic lines were generated and maintained on a C57BL6/J strain background, and C57BL6/J animals were purchased from Charles River Laboratories. The Ncaph2 ${ }^{15 N}$ mutation, previously referred to as Ncaph2 ${ }^{\text {nes }}$, was generated as described (Gosling et al. 2007). All experimental animals were 6 to 12 weeks in age with the exception of Ncaph $2^{115 N / 15 N}$ and Ncaph2 $2^{115 N /+}$ mice used for the $\mathrm{YH} 2 \mathrm{AX}$ flow cytometry in Figure 5. This experiment compared littermates at $16-18$ weeks post partum. Mice were housed in individually ventilated cages with 12 hour light/dark cycles. All tissues were harvested and processed immediately following euthanasia via cervical dislocation.

\section{Generation of Ncaph and Ncaph2 reporter mice.}

Ncaph-AID-mClover and Ncaph2-AID-mClover mice were generated following the Easi-CRISPR protocol (Miura et al. 2018). sgRNAs were designed using the Zhang Lab design tool(crispr.mit.edu) and ordered from IDT. Priority was given to protospacer sequences that would result in cleavage proximal to the stop codon with low predicted likelihood for off-target cleavage. Repair templates were long single stranded oligonucleotides ('megamers') ordered from IDT. Each megamer comprised 105 nucleotides of homology either side of the integrated sequence. Integrated sequences included a flexible linker (Glycine, Glycine, Alanine, Glycine), a mini auxin-inducible degron and mClover. The mini auxin-inducible degron was not used in this study. Full sequences of guide RNA protospacers and repair templates are listed in Appendix S1.

The microinjection mix comprised pre-annealed crRNA/TracrRNA complex $(20 \mathrm{ng} / \mu \mathrm{l})$, repair template $(5 \mathrm{ng} / \mu \mathrm{l})$, and Cas 9 protein $(\mathrm{NEB}-0.3 \mu \mathrm{M})$. This was incubated at $37^{\circ} \mathrm{C}$ for 10 minutes before microinjection. Zygotes were collected from C57BL/6J females mated with overnight with C57BL6/J stud males (Charles River Laboratories). Editing reagents were introduced via intracytoplasmic microinjection at the Evans Transgenic Facility (University of Edinburgh), cultured to the blastocyst stage before transfer to pseudopregnant CD1 females. Successful integrations were identified by PCR using primers spanning the integration sites (Appendix S1), then confirmed by observing band shifts on western blots probed with antibodies against wildtype NCAPH and NCAPH2 (Figure 1C). Founder animals were outcrossed for two generations with C57BL6/J animals and F3 siblings were intercrossed to obtain homozygotes. Animals were genotyped by PCR using primers detailed in Appendix 1. 


\section{Whole Cell Protein Extract Preparation \& Quantification}

All protein preparations were generated from single cell suspensions of primary haematopoietic cells. Single cell suspensions of thymus tissue were generated by gentle dissociation of whole thymus tissue through $40 \mu \mathrm{m}$ filters (Fisherbrand, 22363-547). For bone marrow, tissue was flushed out of tibia and femur bones with PBS before dissociation through a $40 \mu \mathrm{m}$ filter. Cell numbers were counted manually using a haemocytometer. Bone marrow cells were further purified by Magnetic Activated Cell Sorting (Miltenyi), using beads pre-coated with antibodies against B220, Ter-119, CD4 or CD8. MACS purification proceeded according to the manufacturers instructions. Cell pellets were resuspended in NP-40 Lysis Buffer $(150 \mathrm{mM} \mathrm{NaCl}, 50 \mathrm{mM}$ Tris- $\mathrm{HCl}, 1 \% \mathrm{NP}-40)$ using 3 volumes of NP-40 Buffer to 1 volume of cell pellet. $0.5 \mu \mathrm{L}$ benzonase nuclease (Millipore) was added per $100 \mu \mathrm{L}$ of resuspended pellet. Samples were incubated at $4{ }^{\circ} \mathrm{C}$ for 30 minutes with intermittent vortexing, before pelleting cellular debris via centrifugation at maximum speed $\left(13,200 \mathrm{~g}, 15\right.$ minutes, $\left.4{ }^{\circ} \mathrm{C}\right)$. Supernatants were transferred into fresh tubes, and protein concentration was quantified using a Pierce BCA Protein Assay Kit (Thermo, 23228) following manufacturer's instructions.

Pierce Lane Marker Reducing Sample Buffer (1X, Thermo, 39000) was added to each sample prior to denaturation via boiling at $95{ }^{\circ} \mathrm{C}$ for 5 minutes. Samples were used immediately or stored at $-20^{\circ} \mathrm{C}$.

\section{Western Blotting}

Denatured protein lysates (15 $\mu \mathrm{g} / \mathrm{s}$ sample) were loaded on to NuPAGE $4-12 \%$ BisTris $1.0 \mathrm{~mm}$ Mini Protein Gels (Invitrogen, NP0321) alongside Chameleon Duo Protein Ladder ( $3 \mu \mathrm{L} / \mathrm{lane}$; LiCOR, 928-60000) or PageRuler Protein Ladder (5 $\mu \mathrm{L} / \mathrm{lane}$; Thermo Scientific, 26616) and run in pre-chilled 1X MOPS Buffer (Thermo, NP0001). Samples were typically run at 100 Volts for 90 minutes. Transfers were performed using either the iBlot2 Gel Transfer device according to manufacturer's instructions (Figure 1C), or onto Immobilon-P PVDF membranes (Millipore, IPVH00010) via wet transfer (Figures 6B, 6E, and S10C). PVDF membranes were pre-soaked in $100 \%$ methanol (Fisher, 10284580) and rinsed briefly in Transfer Buffer (25 mM Tris (AnalaR, 103156X), 200 mM glycine (Fisher, G-0800-60), 20\% methanol, $0.02 \%$ SDS (IGMM Technical Services)). Genie Blotter transfer device (Idea Scientific) was assembled with the gel and PVDF membrane placed between two layers of cellulose filter paper (Whatman, 3030-917) inside the loading tray. Once the apparatus was prepared, Transfer Buffer was filled to the top of the Genie Blotter and transfer proceeded for 90 minutes at 12 volts.

Conditions for blocking and antibody staining were optimised individually for each probe. Samples were blocked with either $5 \%$ milk powder (Marvel) in TBS (IGMM Technical Services), 0.1\% Tween20 (Figures 6B, 6E, and S10C),, 3\% BSA (Sigma) in TBS, or Intercept (TBS) Blocking Buffer (LiCOR, 927-60001) with constant agitation, either at room temperature for 1 hour, or at $4{ }^{\circ} \mathrm{C}$ overnight.

Primary antibodies were added to the corresponding block solution at the dilution shown in Table S1. Membranes were incubated in the antibody dilutions with constant agitation, either at room temperature for 1 hour, or at $4{ }^{\circ} \mathrm{C}$ overnight. Membranes were washed in TBS-Tween20 solutions $(0.1 \%$ Tween20; 4 washes $x$ 10 minutes). Fluorescent (Figure 1C), or HRP-conjugated (Figures 6B, 6E, and S10C) secondary antibodies were also diluted in the corresponding block solution 
bioRxiv preprint doi: https://doi.org/10.1101/2020.11.04.367847; this version posted November 4,2020 . The copyright holder for this preprint (which was not certified by peer review) is the author/funder, who has granted bioRxiv a license to display the preprint in perpetuity. It is made available under aCC-BY-NC 4.0 International license.

(with $0.1 \%$ Tween20), and membranes were incubated with secondary antibody dilutions under constant agitation at room temperature for 1 hour. Membranes were then washed in TBS-Tween20 solutions ( $0.1 \%$ Tween20, 4 washes $\times 10$ minutes). Membranes were visualised on an Odyssey CLx Imaging System (LiCOR) (Figure 1C) or an ImageQuant LAS 4000 (GE Healthcare) with SuperSignal West Pico PLUS HRP substrate (Thermo Scientific) (Figures 6B, 6E, S10C). Fluorescent antibodies were detected using either a 700 Channel Laser Source $(685 \mathrm{~nm})$ or 800 Channel Laser Source $(785 \mathrm{~nm})$.

\section{Flow Cytometry}

Each sample was prepared from single-cell suspensions of bone marrow and thymus $\left(10 \times 10^{6}\right.$ cells/sample for lineage committed T, B and erythroid cells, $40 \mathrm{x}$ $10^{6}$ sample for LSKs). Fluorescently-conjugated antibodies against cell surface markers were diluted (Table S1) in Flow Cytometry Staining Buffer (eBioscience, 004222-26), and used to resuspend cell pellets before incubation for 15 minutes at 4 ${ }^{\circ} \mathrm{C}$. Samples were then washed in a 10 -fold volume of Flow Cytometry Staining Buffer before centrifugation at $300 \mathrm{~g}$ for 5 minutes at $4^{\circ} \mathrm{C}$. Pellets were resuspended in Cytofix/Cytoperm solution (BD Bioscience, 554722) following manufacturer's instructions and washed in Perm/Wash buffer (BD Bioscience, 554723). Incubation in ice-cold $90 \%$ methanol for 10 minutes at $4 \circ \mathrm{C}$ was performed to further permeabilise samples, which were subsequently washed twice using Perm/Wash buffer. If required, samples were incubated with fluorescently conjugated antibodies against intracellular markers (Table S1) for 20 minutes at room temperature and then washed once using PermAWash solution. Samples were resuspended in DAPI staining solution $(1 \mu \mathrm{g} / \mathrm{mL}$ DAPI in PBS). DAPI-stained samples were incubated at room temperature for at least 15 minutes before acquisition.

Data acquisition (BD LSRFortessa) took place on the same day as sample collection and, for consistency, identical laser power was used to quantify mClover signal between all experiments. Data analysis was conducted using FlowJo software (Treestar). Cellular debris/aggregates were excluded using strict forward- and sidescatter gating strategies (Figure S4). Cell cycle stages were gated based on DNA content (DAPI) fluorescence. Wild-type samples lacking mClover expression were processed and stained in parallel to transgenic samples. To correct for autofluorescence, background fluorescence was measured for each cell population from wild-type samples, and then subtracted from transgenic fluorescence values.

\section{Immunofluorescence microscopy}

Single cell suspensions were obtained from thymus by gentle tissue dissociation through a 40uM filter and from femurs and tibias by flushing bone cavities with PBS. Tissues were collected and processed immediately following termination.

$\mathrm{CD}^{+}$, Ter $119^{+}$or $\mathrm{B} 220^{+}$cells were enriched from thymus or bone marrow by MACS (Miltenyi) purification, according to the manufacturer's instructions, achieving $>90 \%$

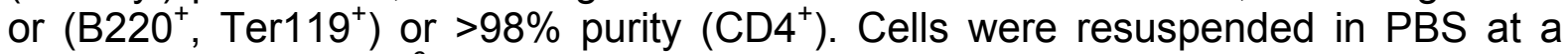
concentration of $5 \times 10^{6} \mathrm{cells} / \mathrm{ml}$. Up to three circles were drawn on each poly-lysine coated glass slide using hydrophobic pen, and the different cell populations were allowed to settle on the same slide at $37^{\circ} \mathrm{C}$. Importantly, this meant that fixation and staining conditions were identical for each cell population to be compared. Cells were fixed in $4 \%$ paraformaldehyde for 10 minutes at room temperature, washed 3 times for 2 minutes in PBS ("washed"), permeabilized in $0.5 \%$ Triton X in PBS for 5 
bioRxiv preprint doi: https://doi.org/10.1101/2020.11.04.367847; this version posted November 4, 2020. The copyright holder for this preprint (which was not certified by peer review) is the author/funder, who has granted bioRxiv a license to display the preprint in perpetuity. It is made available under aCC-BY-NC 4.0 International license.

minutes, washed, blocked in 4\% BSA in PBS for 10 minutes, incubated with primary antibody overnight at $4 \mathrm{C}$, washed, incubated with secondary antibodies for 1 hour at room temperature, washed, incubated in $1 \mathrm{ug} / \mathrm{mL}$ DAPI in PBS for 5 minutes, and then mounted in VectaShield (Vector Laboratories).

Mitotic cells are rare in haematopoietic cell lineages, ranging from 1 in 100 Ter119+ erythroblasts to 1 in 750 thymic T cells. Hence, it was necessary to use pH3S10 as a marker to identify cells of interest. Epifluorescent images were acquired using a Photometrics Coolsnap HQ2 CCD camera and a Zeiss Axiolmager A1 fluorescence microscope with a Plan Apochromat 100x 1.4NA objective, a Nikon Intensilight Mercury based light source (Nikon UK Ltd, Kingston-on-Thames, UK ) and either Chroma \#89014ET (3 colour) or \#89000ET (4 coour) single excitation and emission filters (Chroma Technology Corp., Rockingham, VT) with the excitation and emission filters installed in Prior motorised filter wheels. A piezoelectrically driven objective mount (PIFOC model P-721, Physik Instrumente GmbH \& Co, Karlsruhe) was used to control movement in the $z$ dimension. Hardware control and image capture were performed using Nikon Nis-Elements software(Nikon UK Ltd, Kingston-on-Thames, UK). Deconvolution of 3D data was performed in Nis-Elements (Richardson Lucy, 20 iterations). 3D datasets were visualised and analysed fon DAPI volume and fluorescence intensity using Imaris V9.5 (Bitplane, Oxford Instruments, UK). DNA volume was calculated by manually rendering a surface around the DAPI signal within Imaris, and immunofluorescent signal was calculated from mean voxel intensity within that surface.

Mitotic subphases were distinguished as follows: Prophase/early prometaphase: pH3S10 positive cells without alignment of DAPI-dense chromocenters; late prometaphase/metaphase: $\mathrm{pH} 3 \mathrm{~S} 10$ positive cells with alignment of chromocenters; anaphase: $\mathrm{pH} 3 \mathrm{~S} 10$ positive cells showing evidence for bipolar separation of chromocenters and/or centromeric kleisin foci.

\section{DNA volume following colcemid exposure}

To enrich for prometaphase cells (Figure S8), mice were injected with $200 \mu \mathrm{L}$ colcemid $(200 \mu \mathrm{g} / \mathrm{mL}$ Sigma) and culled after 30 minutes. Tissues were immediately dissected and placed on ice, then processed to single cells and MACS purified as described above. Cells were then fixed in BD Fix/Perm solution for 20 minutes on ice, and washed in PBS. 100 $\mu$ l of cell suspension at an approximate concentration of $1 \times 10^{6} \mathrm{cells} / \mathrm{ml}$ were then adhered to polylysine coated glass slides using a Shandon Cytospin 3 at $600 \mathrm{rpm}$ for 5 minutes. Slides were then permeablised, blocked, and antibody treated as previously. Images were acquired and analysed as described above.

\section{Fluorescence Correlation Spectroscopy}

Tissues harvested from euthanised animals were collected and processed into single cell suspensions as described above, using pre-warmed DMEM (Sigma, D5796). Cell suspensions were diluted in Leibowitz $L-15$ media without phenol red (Gibco, 21083-027) and seeded in Poly-L-Lysine coated $\mu$-Slide 8-well plates (Ibidi, 80824) at a density of $2 \times 10^{6}$ cells/well. Samples were allowed to settle on the slides for 20 minutes at $37{ }^{\circ} \mathrm{C}$. To stain for DNA content, SiR-DNA (Spirochrome, SC007) was added to samples at a 1 in 20,000 dilution immediately prior to imaging. Samples were imaged for no longer than 3 hours after initial seeding onto slides. 
FCS measurements of endogenous NCAPH-mClover and NCAPH2-mClover in ES cells, primary bone marrow cells and thymocytes were performed using a PicoQuant modified Leica SP5 microscope to enable FCS and FLIM capabilities, which features Avalanche PhotoDiodes that enable close to single-photon detection (1). The detection efficiency of CLSM imaging was significantly improved by the introduction of APD detectors. As compared to PMTs, which are normally used as detectors in conventional CLSM, the APDs are characterized by higher quantum yield and collection efficiency - about $70 \%$ in APDs as compared to $15-25 \%$ in PMTs, higher gain, negligible dark current and better efficiency in the red part of the spectrum. Enhanced fluorescence detection efficiency enabled image collection using fast scanning $(1-5 \mu \mathrm{s} / \mathrm{pixel}$ ). This enhances further the signal-to-noise-ratio by avoiding fluorescence loss due to triplet state formation and, thereby, enabling fluorescence imaging with single-molecule sensitivity. In addition, low laser intensities $(150-750 \mu W)$ could be applied for imaging, significantly reducing the phototoxicity(Vukojevic et al. 2010).

FCS measurements are performed by recording fluorescence intensity fluctuations in a very small, approximately ellipsoidal observation volume element (OVE) (about $0.2 \mu \mathrm{m}$ wide and $1 \mu \mathrm{m}$ long) that is generated in cells by focusing the laser light through the microscope objective and by collecting the fluorescence light through the same objective using a pinhole in front of the detector to block out-of-focus light. The fluorescence intensity fluctuations, caused by fluorescently labelled molecules passing through the OVE, are analysed using temporal autocorrelation analysis.

In temporal autocorrelation analysis we first derive the autocorrelation function $G(\tau)$ :

$G(\tau)=1+\frac{\langle\delta I(t) \cdot \delta I(t+\tau)\rangle}{\langle I(t)\rangle^{2}}(\mathrm{~S} 1)$,

where $\delta I(t)=I(t)-\langle I(t)\rangle$ is the deviation from the mean intensity at time $t$ and $\delta I(t+\tau)=I(t+\tau)-\langle I(t)\rangle$ is the deviation from the mean intensity at time $t+\tau$. For further analysis, an autocorrelation curve is derived by plotting $G(\tau)$ as a function of the lag time, i.e. the autocorrelation time $\tau$.

To derive information about molecular numbers and their corresponding diffusion time, the experimentally obtained autocorrelation curves are compared to autocorrelation functions derived for different model systems, and the model describing free three dimensional (3D) diffusion of two components and triplet formation was identified as the simplest and best suited for fitting the experimentally derived autocorrelation curves, and was used throughout:

$$
G(\tau)=1+\frac{1}{N}\left(\frac{1-y}{\left(1+\frac{\tau}{\tau_{D_{1}}}\right) \cdot \sqrt{1+\frac{w_{x y}^{2} \tau}{w_{z}^{2} \tau_{D_{1}}}}}+\frac{y}{\left(1+\frac{\tau}{\tau_{D_{2}}}\right) \cdot \sqrt{1+\frac{w_{x y}^{2} \tau}{w_{z}^{2} \tau_{D_{2}}}}}\right)\left(1+\frac{T}{1-T} e^{-\frac{\tau}{\tau_{T}}}\right)
$$


In the above equation, $N$ is the average number of fluorescent molecules in the OVE; $y$ is the fraction of the slowly moving fluorescent molecules; $\tau_{D_{1}}$ is the diffusion time of the free molecules; $\tau_{D_{2}}$ is the diffusion time of fluorescent molecules undergoing nonspecific interactions with the DNA; $w_{x y}$ and $w_{z}$ are radial and axial parameters, respectively, related to spatial properties of the OVE; $T$ is the average equilibrium fraction of molecules in the triplet state; and $\tau_{T}$ the triplet correlation time related to rate constants for intersystem crossing and the triplet decay. Spatial properties of the detection volume, represented by the square of the ratio of the axial and radial parameters $\left(\frac{w_{z}}{w_{x y}}\right)^{2}$, are determined in calibration measurements performed using a solution of Alexa488 or Alexa568 dyes for which the diffusion coefficient (D) is known. The diffusion time $\tau_{D}$, measured by FCS, is related to the translation diffusion coefficient $D$ by:

$\tau_{D}=\frac{w_{x y}^{2}}{4 D}(\mathrm{~S} 3)$

Fluorescence intensity fluctuations were recorded for $50 \mathrm{~s}$ lor 100 s per FCS measurement. Autocorrelation curves were calculated and analysed using the SymphoTime 64 software package (PicoQuant). The nonlinear least square fitting of the autocorrelation curves was performed using the Levenberg-Marquardt algorithm. Quality of the fitting was evaluated by visual inspection and by residuals analysis. Control FCS measurements to assess the detection volume were routinely performed prior to data acquisition, using dilute solutions of known concentration of Alexa488 and Alexa568 dyes (Petrášek and Schwille 2008; Montis et al. 2014).

In order to ascertain that the interpretation and fitting of FCS curves is correct, we have: (1) tested several laser intensities in our FCS measurements and have utilized the lowest laser intensity, for which the highest counts per second and molecule (CPSM) were obtained, while limiting photobleaching; and (2) we have established that CPSM do not change among FCS measurements performed. Moreover, we have previously shown that both characteristic decay times increase when the size of the OVE is increased(Papadopoulos et al. 2019; Vukojevic et al. 2010). Together, these lines of evidence indicate that both the short and long characteristic decay times are generated by molecular diffusion rather than by photophysical and/or chemical processes such as mClover protonation/deprotonation. (3) We have ascertained that the long characteristic decay time of our FCS measurements is not the result of photobleaching and that differences in the relative amplitudes of the fast and slow diffusing components reflect differences in their concentrations among cells.

\section{Sucrose Gradient Centrifugation}

$5-20 \%$ sucrose gradients were prepared on a Biocomp Gradient Station IP from 5\% and $20 \%$ solutions of sucrose in gradient buffer $(50 \mathrm{mM}$ Tris $\mathrm{HCl} \mathrm{pH} 7.5,150 \mathrm{mM}$ $\mathrm{NaCl}, 1 \mathrm{mM}$ EDTA) to Seton tubes (Beckman Coulter). Single cell suspensions of approximately $3 \times 10^{8}$ cells from thymus and bone marrow were obtained as above,

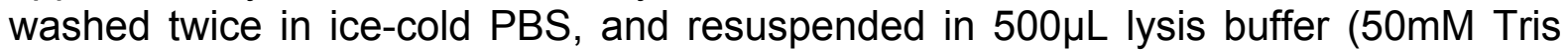

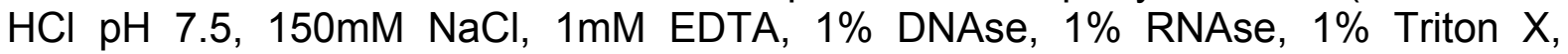
protease inhibitors), incubated on ice for 30 minutes, before being pelleted by centrifugation $\left(14,000 \mathrm{rpm}, 5\right.$ minutes, $\left.4^{\circ} \mathrm{C}\right)$ and supernatant was loaded onto 
gradients. Gradients were placed in pre-cooled cradles and loaded onto an SW41 TI rotor in a Beckman Coulter Optima L-90K Ultracentrifuge, then centrifuged for 16 hours at $32.4 \mathrm{k}$ RPM, 4oC. Following centrifugation, 24 fractions were removed manually and placed in precooled Eppendorfs and subjected to TCA precipitation. Protein samples were resuspended in $30 \mu \mathrm{l}$ 1x NuPage LDS Sample Loading Buffer with 1x Sample Reducing Agent, incubated at $97^{\circ} \mathrm{C}$ for 5 minutes, and centrifuged (14,000rpm, 5 minutes). The supernatant was separated alongside a PageRuler Prestained Protein Ladder (10 to $180 \mathrm{kDa}$ ) on a NuPage $4-12 \%$ Bis-Tris Midi gel, then transferred onto Immobilon-P PVDF membrane and probed with antibodies as described above, and condensin antibodies were visualised using SuperSignal West Pico HRP substrate (ThermoFisher) on an ImageQuant LAS 4000 (GE Healthcare).

\section{nCAPH2 antibody generation}

nCAPH2 antibodies were produced by Proteintech. Recombinant fragments (aa 267-607 and aa1-394) were expressed, purified, and used as antigens to immunize rabbits. Antibody specificity was confirmed by observing band shifts on western blots performed using wildtype and transgenic material (e.g. Figure 1C).

\section{Immunoprecipitation and mass spectrometry}

Single cells from whole thymus and bone marrow were extracted as described above and lysed in $1 \%$ triton buffer $(20 \mathrm{mM}$ Tris- $\mathrm{HCl}, 137 \mathrm{mM} \mathrm{NaCl}, 1 \%$ triton $\mathrm{X}-100,2 \mathrm{mM}$ EDTA, protease inhibitors (Calbiochem), phosphatase inhibitors). Protein was quantified by BCA assay as described above. $1 \mathrm{mg}$ of total protein was used for Mass Spectrometry. IP was performed on a Kingfisher Duo robot using $1 \mu \mathrm{g}$ of anti-SMC4 (Bethyl) or Rabbit dgG (CST) antibody, magnetic beads, and $500 \mu$ l of lysate at $2 \mathrm{mg} / \mathrm{mL}$. Lysate, antibodies and beads were incubated with mixing at $5 \circ \mathrm{C}$ for 2 hours, then beads were transferred for two washes in lysis buffer without detergent, and three washes in TBS. Following tryptic digest (2M urea, $100 \mathrm{mM}$ tris, $1 \mathrm{mM}$ DTT, $5 \mathrm{ug} / \mathrm{mL}$ trypsin), peptides were separated and ionised on Ultimate 3000 series Nano UHPLC using a C18 RP packed emitter in a column oven (lonOpticks, Sonation, Proxeon). Ionised peptides were analysed on an Orbitrap Fusion Lumos (Thermo) in data-dependent mode and searched against the 2018_01 release of Uniprot mouse reference proteome using MaxQuant version 1.6.1.0, with LFQ (Cox et al. 2014). Statistical analysis was conducted using Wasim Aftab's implementation of Kammers et al 2015 \{https://github.com/wasimaftab; (Kammers et al. 2015). Proteins that were called as significantly enriched in the SMC4-IP compared to IgG control displayed at least a 16 -fold enrichment in LFQ signal $\left(\log _{2} F C \geq 4\right)$ and a p-value of $<1 \times 10^{-2}$. To calculate the recovery of each condensin I subunit in the SMC4 immunoprecipitation relative to the SMC4 bait, we first subtracted LFQ values from the IgG control condition $(n=4)$ from LFQ values from the SMC4 IP $(n=4)$. The mean IgG-corrected value for the SMC4 bait was then assigned a value of 1 , and the IgG corrected LFQ values $(n=4)$ for each of the other 4 subunits was expressed relative to this.

\section{Murine Embryonic Fibroblast (MEF) derivation and culture}

MEFs were derived from E13.5 embryos. Head and organs were removed, and body was homogenized with a sterile razor blade. $1 \mathrm{~mL} 1 \mathrm{x}$ Trypsin (Sigma-Aldrich) in PBS was added per 3 embryos and the mixture was incubated at $37 \circ \mathrm{C}$ for 10 minutes. Tissue was further homogenized by passage through an 236 needle approximately 20 times. Homogenous tissue was then resuspended in MEF media (Standard DMEM (Life Technologies) with $15 \% \mathrm{v} / \mathrm{v}$ foetal calf serum, penicillin 
$(10,000$ units $/ \mathrm{mL})$ and streptomycin $(650 \mu \mathrm{g} / \mathrm{mL}), 0.3 \mathrm{mg} / \mathrm{mL}$ L-Glutamine, $1 \mathrm{mM}$ sodium pyruvate (Gibco), $0.1 \mathrm{mM} \beta$-mercaptoethanol, $1 \mathrm{x}$ Non Essential Amino Acids (Sigma)) and passed through a $40 \mu \mathrm{m}$ filter to remove non homogenous tissue. Single cell suspension was then cultured in a T75 flask per 3 embryos at $37 \circ \mathrm{C}, 5 \%$ $\mathrm{CO}_{2}$, and $3 \% \mathrm{O}_{2}$.

\section{Methods References}

Cox J, Hein MY, Luber CA, Paron I, Nagaraj N, Mann M. 2014. Accurate proteomewide label-free quantification by delayed normalization and maximal peptide ratio extraction, termed MaxLFQ. Mol Cell Proteomics 13: 2513-2526.

Gosling KM, Makaroff LE, Theodoratos A, Kim Y-H, Whittle B, Rui L, Wu H, Hong NA, Kennedy GC, Fritz J-A, et al. 2007. A mutation in a chromosome condensin II subunit, kleisin $\beta$, specifically disrupts $T$ cell development. Proceedings of the National Academy of Sciences 104: 12445-12450.

Kammers K, Cole RN, Tiengwe C, Ruczinski I. 2015. Detecting Significant Changes in Protein Abundance. EuPA Open Proteom 7: 11-19.

Miura H, Quadros RM, Gurumurthy CB, Ohtsuka M. 2018. Easi-CRISPR for creating knock-in and conditional knockout mouse models using long ssDNA donors. Nat Protoc 13: 195-215.

Montis C, Baglioni P, Berti D, 2014. Monitoring the interaction of nucleolipoplexes with model membranes. Soft Matter 10: 39-43.

Papadopoulos DK, Skouloudaki K, Engstrom Y, Terenius L, Rigler R, Zechner C, Vukojevic V, Tomancak P. 2019. Control of Hox transcription factor concentration and cell-to-cell variability by an auto-regulatory switch. Development dev.168179.

Petrášek Z, Schwille P. 2008. Precise Measurement of Diffusion Coefficients using Scanning Fluorescence Correlation Spectroscopy. Biophysical Journal 94: 14371448.

Vukojevic V, Papadopoulos DK, Terenius L, Gehring WJ, Rigler R. 2010. Quantitative study of synthetic Hox transcription factor-DNA interactions in live cells. Proc Natl Acad Sci USA 107: 4093-4098. 
A

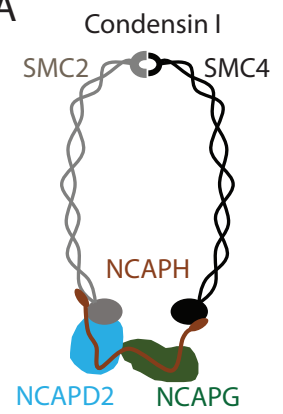

$\mathrm{D}$
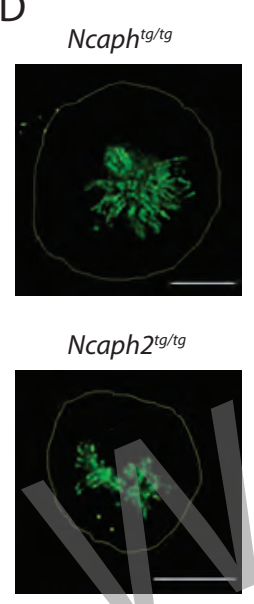

Condensin II

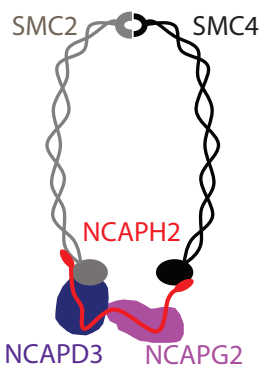

B

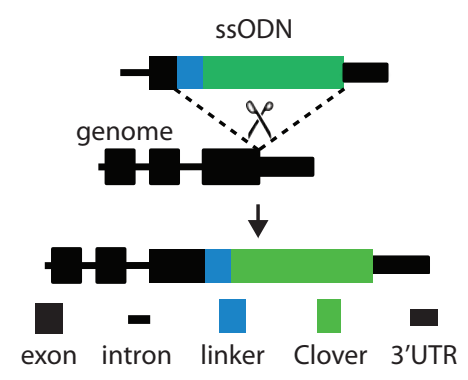

C

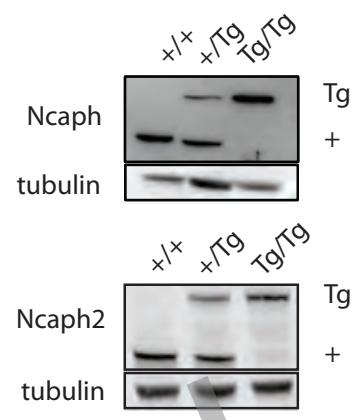

$E$

Genotype Expected Observed

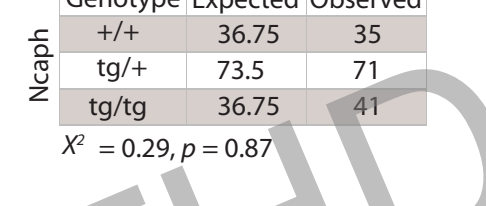

Genotype Expected Observed

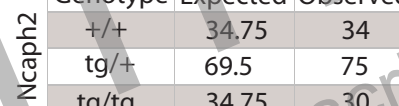

$\mathrm{tg} / \mathrm{tg} \quad 34.75, \mathrm{~S}^{30}$

$X^{2}=0.65, p=0.72$
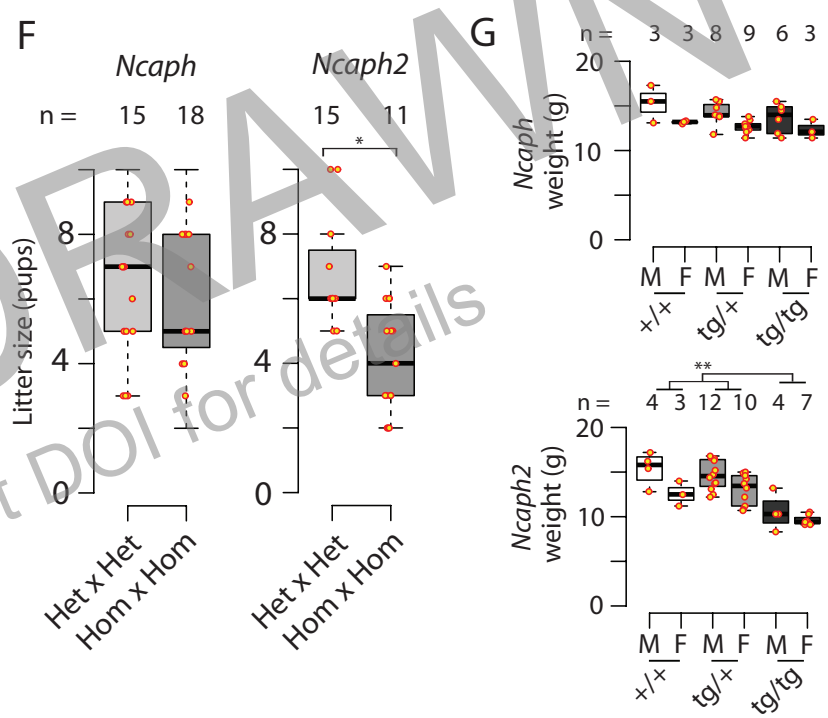

Figure 1: Generation of Ncaph and Ncaph2 fluorescent reporter mouse models.

A. Schematic diagrams showing the subunits of condensin I and II complexes. The kleisin subunits of condensin I and II are Ncaph and Ncaph2, respectively. B. CRISPR-Cas9 strategy for integrating mClover cassettes at the Ncaph and Ncaph2 loci using long single stranded deoxyoligonucleotides (ssODN) to generate $N \mathrm{Ncaph}^{\text {tg }}$ and $\mathrm{Ncaph2^{tg }}$ alleles. Full details and sequences for the integrated cassettes are given in Appendix 1. C. Western blots prepared from thymic whole cell protein extract were probed with antibodies recognising endogenous Ncaph and Ncaph2. ' + ' indicates wildtype allele, 'tg' indicates transgenic. D. Immunofluorescence imaging of mitotic murine embryonic fibroblast lines derived from $\mathrm{Ncaph}^{\text {tg/tg }}$ and Ncaph2 $2^{\text {tg/tg }}$ embryos, showing expected pattern of chromosomal localisation. Scale bar $=5 \mu \mathrm{m}$ E. Observed and expected genotype frequencies among 28 day-old animals generated from heterozygous crosses for each transgene. Chi-squared tests revealed no significant deviation from expected mendelian frequencies. $\mathbf{F}$. Litter sizes from matings between animals heterozygous versus homozygous for $N c a p h^{t g}$ (top) and Ncaph2 $2^{\text {tg }}$ (bottom) reporter transgenes. * indicates significant difference at $p<1 \times 10^{-3}$ from unpaired two-tailed t-tests $\mathbf{G}$. Weight of pups at 28 days post-partum. $M=$ male, $F=$ female, ${ }^{* *}$ indicates significant differences between genotypes $\left(M+F\right.$ combined) at $p<1 \times 10^{-4}$ (one-way ANOVA with Tukey's HSD posthoc test). 
A

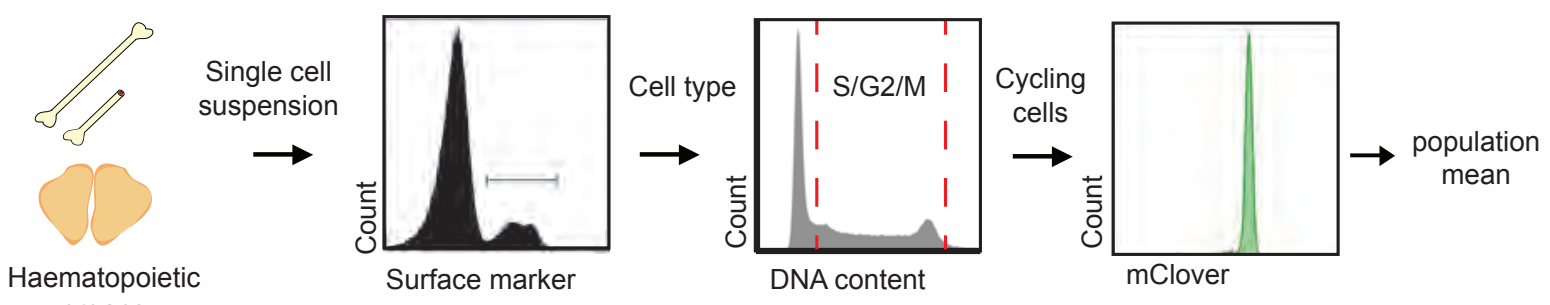
organs

B

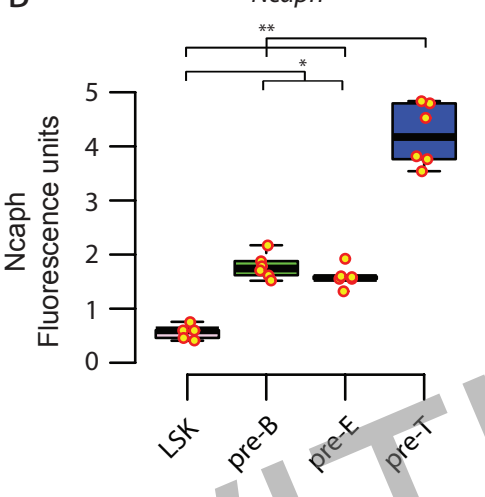

C

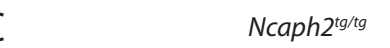

D

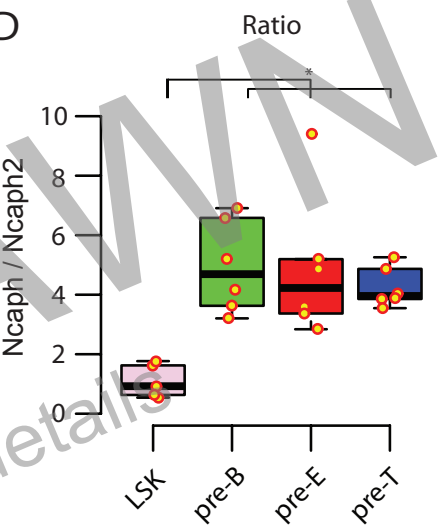

Figure 2: Dynamic condensin expression levels during haematopoietic differentiation

A. Diagram showing the generic flow cytometry workflow used to quantify reporter transgene in specific cell lineages, at specific cell cycle phases. mClover expression in panels $B-D$ was calculated specifically from cells in S/G2/M. Full gating details are shown in Figure S2. B \& C. Mean mClover fluorescence from different haematopoietic populations of Ncaph (B) and Ncaph2 (C) transgenic animals. Each data point represents the mean background-corrected mClover fluorescence for at least 400 (LSK) or 3000 (pre-B, pre-E, pre-T) cells from each of $n=5$ (LSK) or 6 (pre-B, pre-E, pre-T) animals collected over two independent experiments. D. The ratio of Ncaph to Ncaph2 expression in each cell population shown in panels $B$ \& $C$. * indicates significant differences at $p<0.05,{ }^{* *}$ at $p<1 \times 10^{-3}$, ${ }^{* * *}$ at $p<1 \times 10^{-6}$ (one-way ANOVA with Tukey's HSD posthoc test). 
bioRxiv preprint doi: https://doi.org/10.1101/2020.11.04.367847; this version posted November 4, 2020. The copyright holder for this preprint (which was not certified by peer review) is the author/funder, who has granted bioRxiv a license to display the preprint in perpetuity. It is made available under aCC-BY-NC 4.0 International license.

A

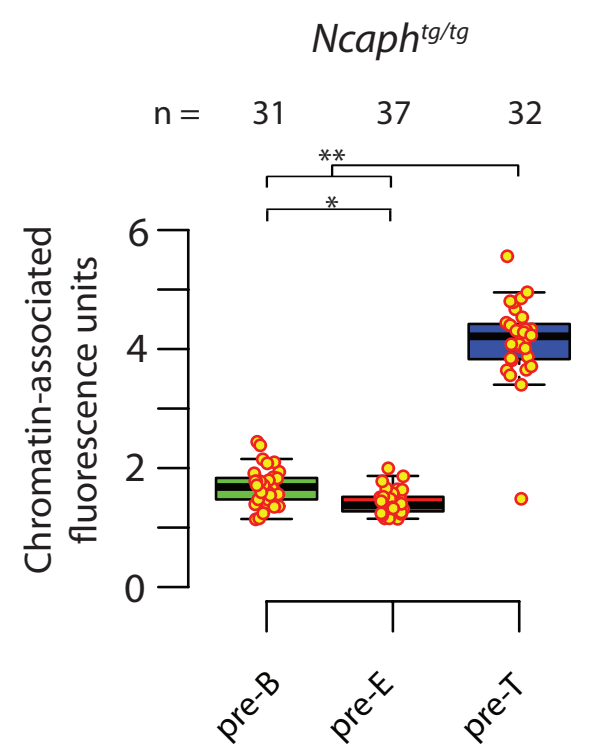

C

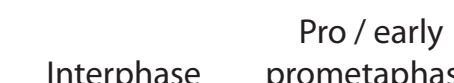

iii

iv

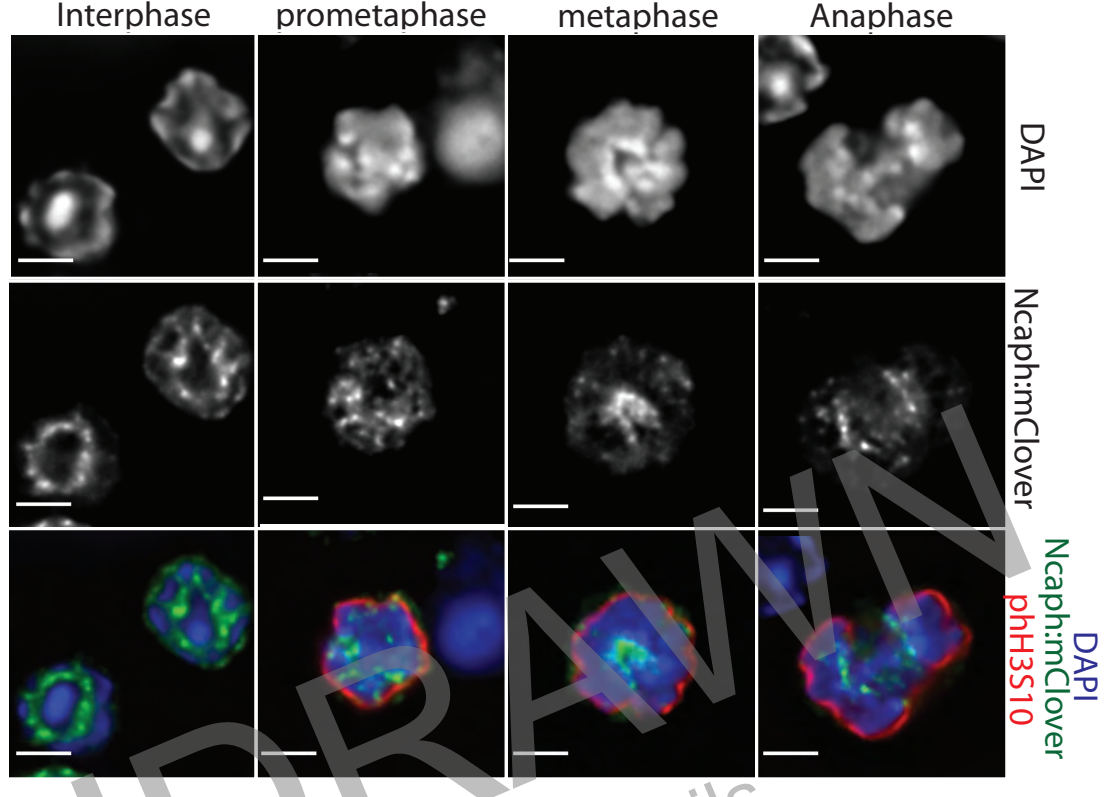

B

D Pro/early Late prómeta /

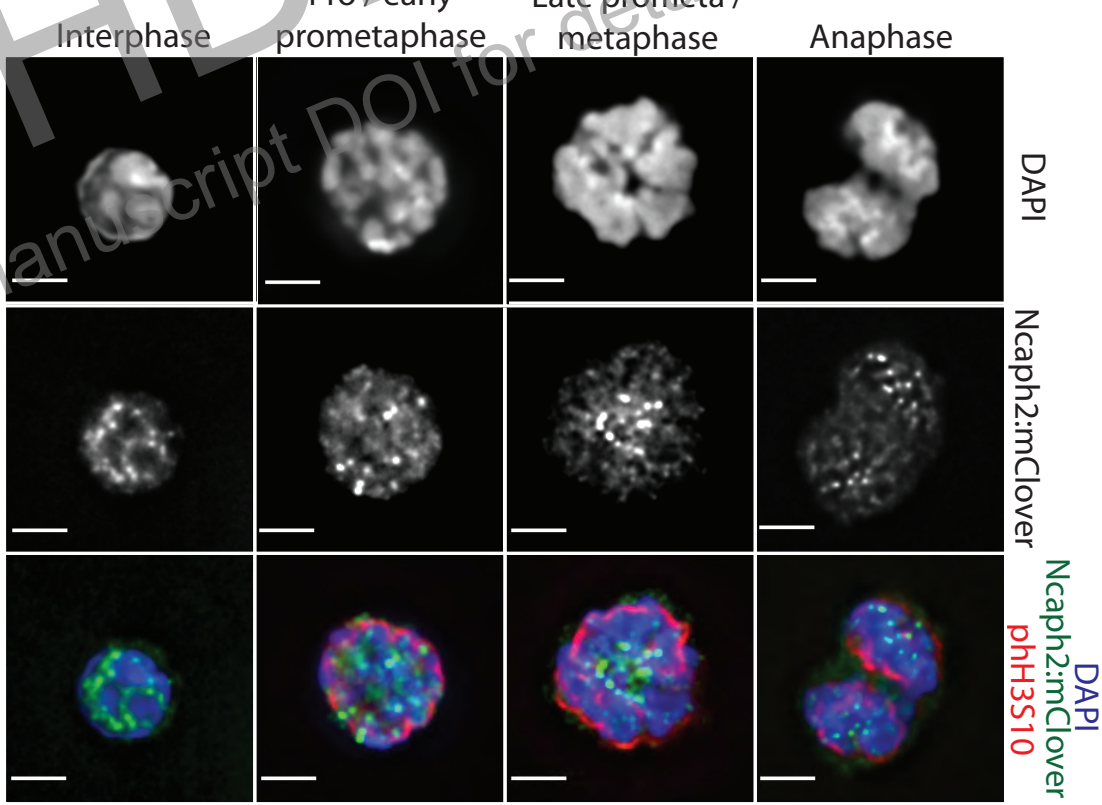

Figure 3: Condensin expression and localisation during haematopoietic mitoses

A \& B Quantitation of Ncaph (A) and Ncaph2 (B) signal colocalised with chromosomes of cells in late prometaphase / metaphase. Cells were magnetically purified from bone marrow $\left(B 220^{+}\right.$pre-B cells, Ter $119^{+}$Erythroid (pre-E) cells) and thymus (CD8 ${ }^{+}$pre-T cells). The developmental status of mitotic cells within each lineage is shown in Figure S4A, S4B and S4C. DAPI signal was used to segment mitotic chromosomes in $3 \mathrm{D}$, and total kleisin fluorescence (mClover fluorescence plus GFP booster) was quantified specifically within this volume. * indicates significant differences between groups at $p<0.05,{ }^{* *}$ indicates $p<1 \times 10^{-7}$ from one-way ANOVA with Tukey's HSD posthoc test. Data are from a single experiment. C \& D. Representative immunofluorescence images of pre-T cells (CD8+) during interphase and different mitotic subphases (i) to iv) from $\mathrm{Ncaph}^{\text {tg/tg }}$ (C) and Ncaph2 ${ }^{\text {tg/tg }}$ (D) animals. Representative images from pre-B and pre-E cells are shown in Figure S5. Signal from the mClover/488 channel was adjusted in this image series to enable kleisin localisation to be visualised across diverse expression levels. For comparison, images from the same cells without signal adjustment are shown in Figure S7. Images show single z-planes, scale bar $3 \mu \mathrm{m}$. A large majority of pH3S10 positive cells was in early or late prometaphase (images representative of $>30$ cells per lineage). Anaphase cells were extremely rare (images representative of 1 to 5 cells per lineage). 
A.
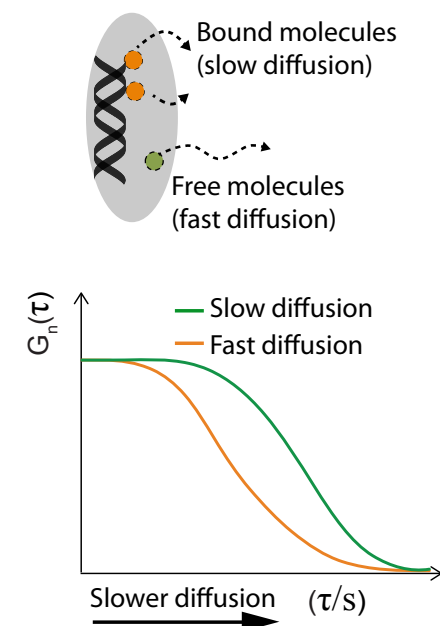

$\mathrm{E}$
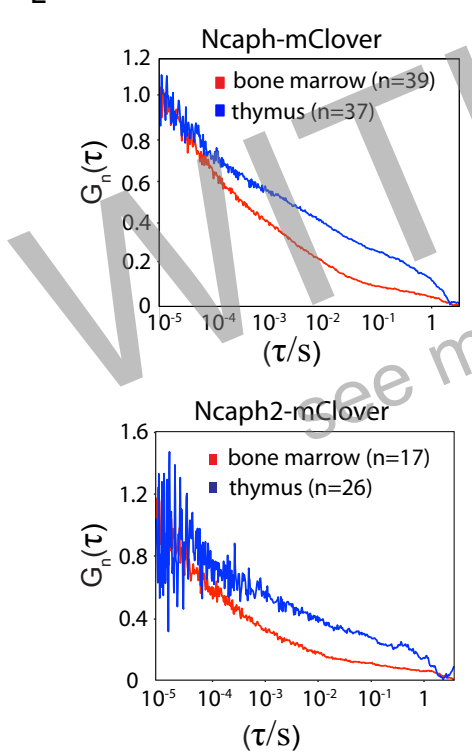

B.

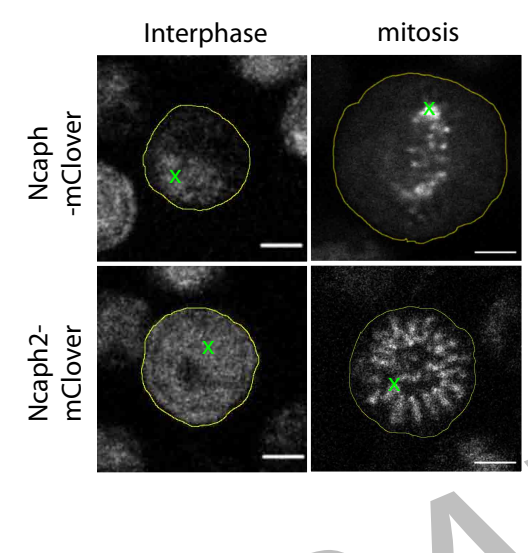

C.

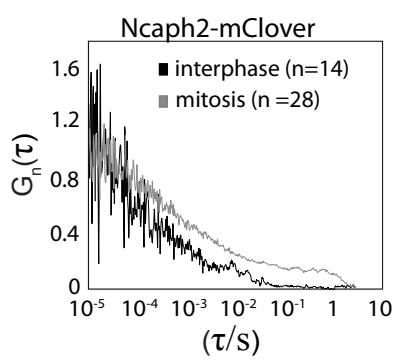

D.

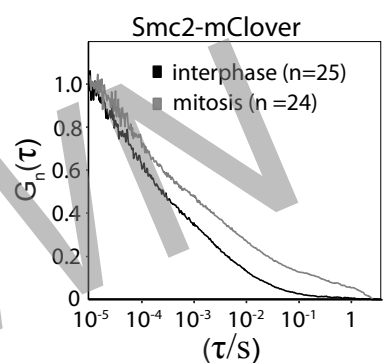

$\mathrm{H}$
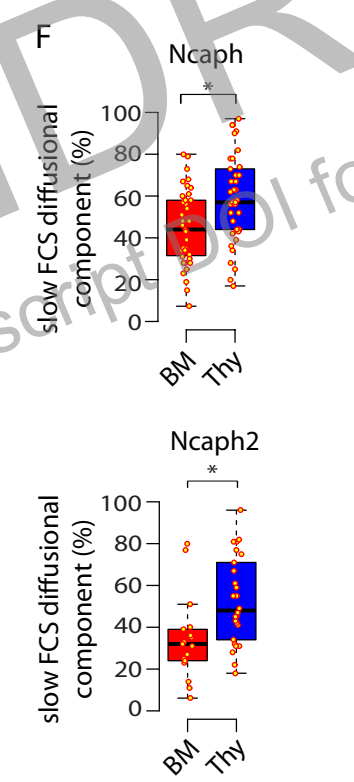

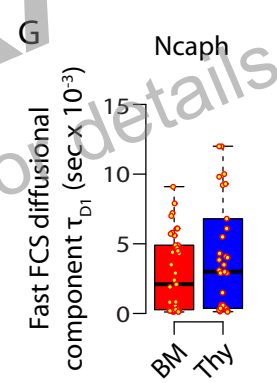

Ncaph2

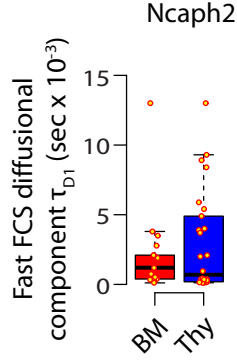

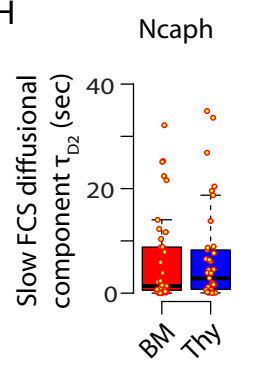

Ncaph2

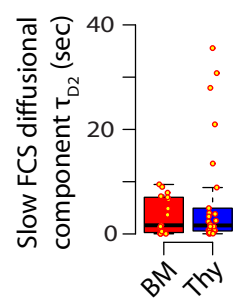

\section{Figure 4: Tissue-specific mobility of Ncaph and Ncaph2 during mitosis}

A. Schematic illustrating the use of Fluorescence Correlation Spectroscopy (FCS) in these experiments. Grey ellipse represents the detection volume. See Methods for further details. B. Single z-plane images show representative measurement points from interphase and mitotic cells. Green ' $x$ 's indicate the representative regions where measurements were performed. Scale bar $=2$ $\mu \mathrm{m}$ C. Autocorrelation curves normalised to the same amplitude $(G(\tau)=1$ at the zeroth lag time) show a shift of the FCS curve, recorded at mitosis in thymocytes, towards longer characteristic decay times for Ncaph2-mClover relative to interphase, indicating more or longer-lasting interactions of Ncaph2-mClover with DNA. In panels $\mathrm{C}$ to $\mathrm{F}, \mathrm{n}$ indicates the number of FCS measurements used to generate curves, with each measurement from a different cell. $\mathbf{D}$. As for panel $\mathrm{C}$, with measurements from a mouse embryonic stem cell line with mClover homozygously fused to Smc2. For panels E - I, Ncaph-mClover is shown in the upper and Ncaph2-mClover in the lower position. E. Autocorrelation curves show slower mobility in mitotic thymocytes compared to bone marrow cells. Data were pooled from two independent experiments. F. Box and stripplots show the fraction of the slow component after fitting with a two-component diffusion model (Methods). Asterisks indicate statistically significant difference at $p<0.01$ from two-tailed unpaired t-tests. G \& H. Boxplots show the characteristic decay times $\left(\tau_{D 1}\right.$ and $\left.\tau_{D 2}\right)$ of the FCS measurements obtained after fitting. Differences were not significant at $p<0.05$ in 2-tailed unpaired t-tests. 
bioRxiv preprint doi: https://doi.org/10.1101/2020.11.04.367847; this version posted November 4, 2020. The copyright holder for this preprint (which was not certified by peer review) is the author/funder, who has granted bioRxiv a license to display the preprint in perpetuity. It is made available under aCC-BY-NC 4.0 International license.

A

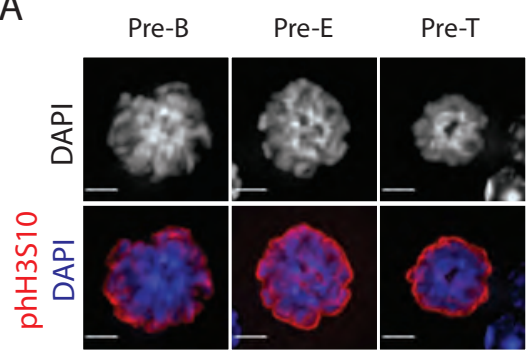

D

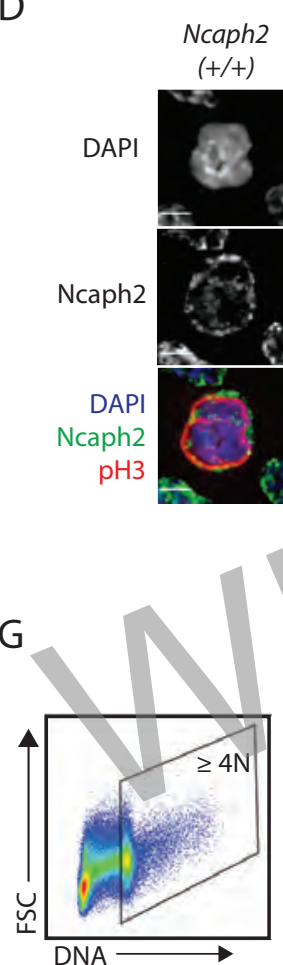

B $\quad \mathrm{n}=1919 \quad 16$

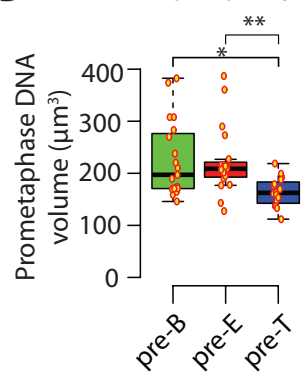

$E$

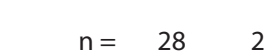

C
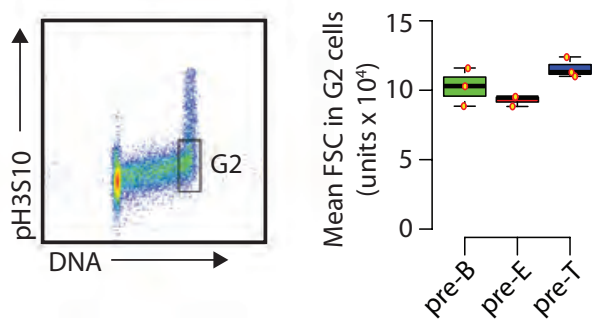

$\mathrm{F}$

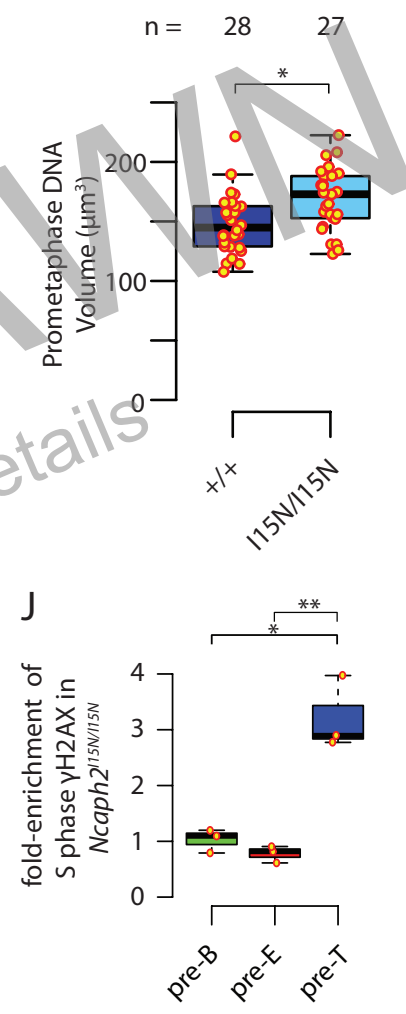

Figure 5. Functional consequences of condensin dosage in haematopoietic precursors

A. Representative images of late prometaphase / metaphase bone marrow B cells (B220 ${ }^{+}$pre-B), bone marrow erythroid precursors $\left(T_{e} 119^{+}\right.$pre-E), and thymic $T$ cells $\left(C D 8^{+}\right.$pre-T) from wildtype mice. Cells were purified and stained as described in Figure 3. Late prometaphase / metaphase cells were identified based on alignment of DAPI-dense centromeric regions. Scale bar $3 \mu \mathrm{m}$ B. DNA volume was measured following segmentation of DAPI stained chromosomes of cells represented in panel A. * indicates $p<$ $0.02,{ }^{* *}$ indicates $p<0.01$ from one-way ANOVA with Tukey's HSD posthoc test. C. Single cells were gated on lineage markers as described in Figure 2A, then G2 cells were gated as shown in the left panel (4N DNA content, phosphoH3 negative). Mean Forward Scatter (FSC) values from $>1000$ G2 cells per replicate $(n=3$ from independent experiments) are shown on the right. Differences between groups were not significant at $p<0.05$ in a one-way ANOVA. D. Immunofluorescence images of mitotic thymocytes from wildtype and Ncaph $2^{115 N / 15 N}$ mice. DAPI signal was used to segment mitotic chromatin in 3 dimensions. Scale bar $3 \mu \mathrm{m}$ E. Quantification of Ncaph2 fluorescence within DAPI stained regions of prometaphase cells as shown in panel $D$. * indicates significant difference at $p<1 \times 10^{-3}$ from two-tailed ttest. F. DNA volume was measured following segmentation of DAPI stained chromosomes of cells represented in panels $D \& E$. * indicates significant difference at $p<5 \times 10^{-3}$ from two-tailed t-test. G. The percentage of cells with $4 \mathrm{~N}$ or greater DNA content (a proxy for tetraploidy) was calculated as shown. At least 100,000 cells were analysed per sample $\mathbf{H}$. The fold increase in $\%$ tetraploidy in different cell types homozygous versus heterozygous for the $N$ caph $2^{115 N}$ mutation. I. Gating of $S$ phase cells for flow cytometric quantification of $\mathrm{yH} 2 \mathrm{Ax}$. J. Mean $\mathrm{yH} 2 \mathrm{Ax}$ signal was calculated from $>1000 \mathrm{~S}$ phase cells in $\mathrm{B}$ cell $\left(\mathrm{B}_{220^{+}}\right.$pre-B) Erythroid $\left(\mathrm{Ter}_{119^{+}}\right.$pre-E) and T cell (total thymocyte, pre-T) precursors. The fold increase in mean $\mathrm{yH} 2 \mathrm{Ax}$ signal in different cell types homozygous versus heterozygous for the Ncaph2 $2^{15 N}$ mutation is shown. For panels $\mathrm{H} \& \mathrm{~J}$, * indicates significant difference at $\mathrm{p}<2 \times 10^{-3}$, ** at $\mathrm{p}<$ $1 \times 10^{-3}$, from one-way ANOVA with Tukey's HSD posthoc test. 
A

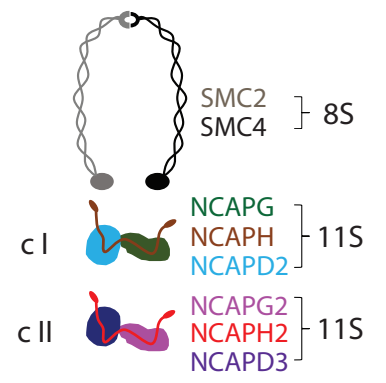

B

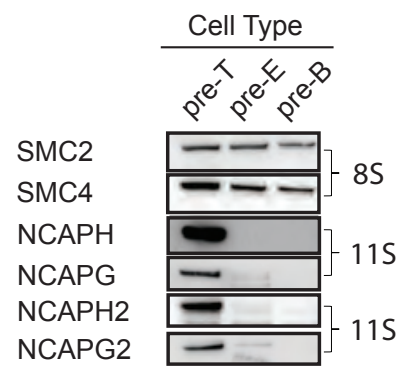

C

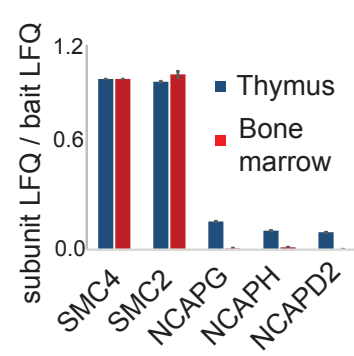

D

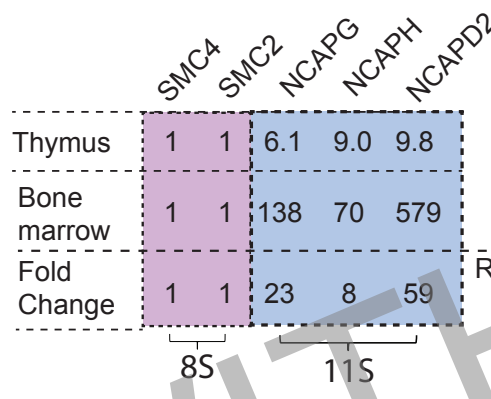

LFQ

Fold-depletion vs SMC4

Reduction in BM
E

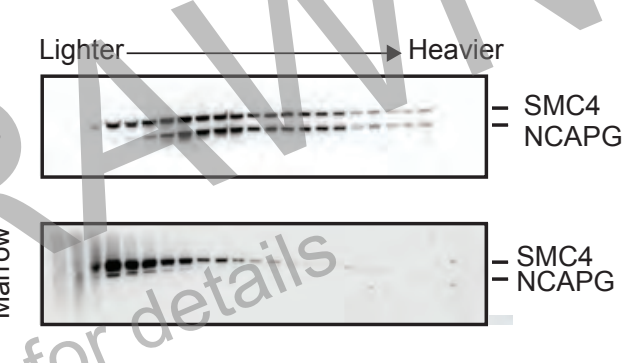

Figure 6: The availability of non-SMC subunits controls the formation of condensin holocomplexes during development

A. Schematic showing subunit composition of the $8 \mathrm{~S}$ and $11 \mathrm{~S}$ subcomplexes of condensin I (c I) and II (c II). B. Western blots from whole cell extract of wildtype thymocytes (pre-T), MACS-purified bone marrow B cells (B220 ; pre-B) and erythroid cells (Ter- $119^{+}$; pre-E) probed with polyclonal antibodies against condensin subunits. Common loading controls (Gapdh, actb, histone H3) showed consistently more diverse expression than Smc2 across cell types, and are therefore not shown. C \& D. Relative enrichment of condensin I subunits following Smc4 IP from thymus and bone marrow whole cell extract. The Label Free Quantification (LFQ) signal of the SMC4 bait was assigned the value of 1, then values for other subunits were expressed relative to this. Data are presented in histogram (C) and table (D) format. E. Western blots generated from thymus (top) and bone marrow (bottom) whole cell extract fractionated by sucrose gradient centrifugation, then probed with antibodies against Smc4 and Ncapg. The lower band (Ncapg) was not detected in the bone marrow sample. 
A

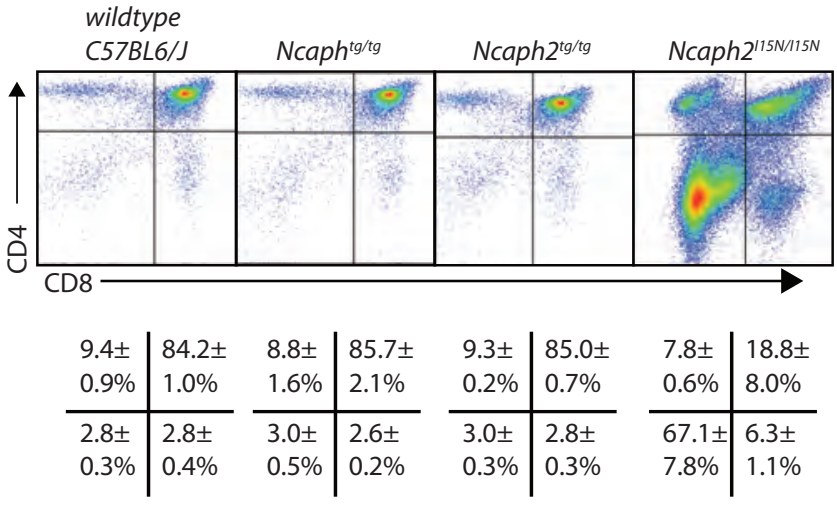

B

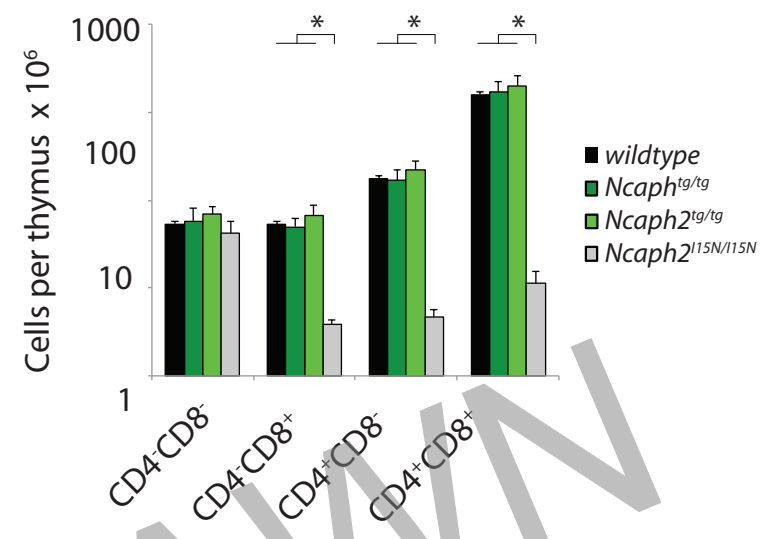

Figure S1: Thymic T cell development is not perturbed in condensin reporter mice.

A. Dotplots show the distribution of T cell precursor subsets in thymus from wildtype, Ncaph and Ncaph2 reporter transgenic, and Ncaph2 $2^{115 N / 15 N}$ mice. Mean and standard deviation from $\mathrm{n}=3$ animals from a single experiment are shown below the plots. $B$. Absolute numbers of precursor subsets from the experiment shown in panel $B$. *indicates significant differences at $p<0.01$ from one-way ANOVA with Tukey's HSD test. 
bioRxiv preprint doi: https://doi.org/10.1101/2020 11.04.367847: this version posted November 4, 2020. The copyright holder for this preprint (which was not certified by peer review) is the author/funder, who has granted bioRxiv a license to display the preprint in perpetuity. It is made available under aCC-BY-NC 4.0 International license.

A

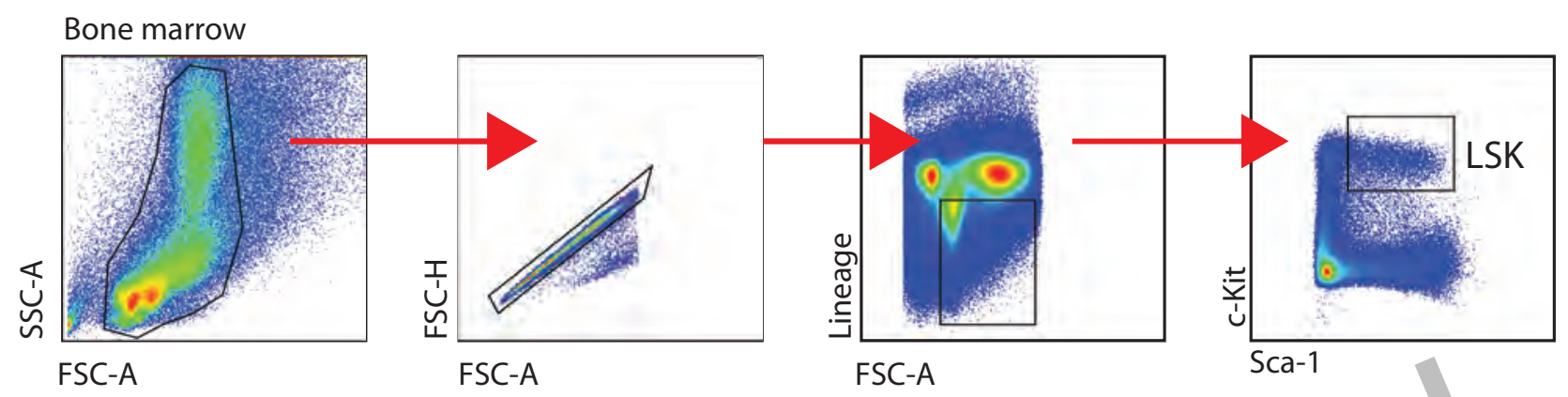

B

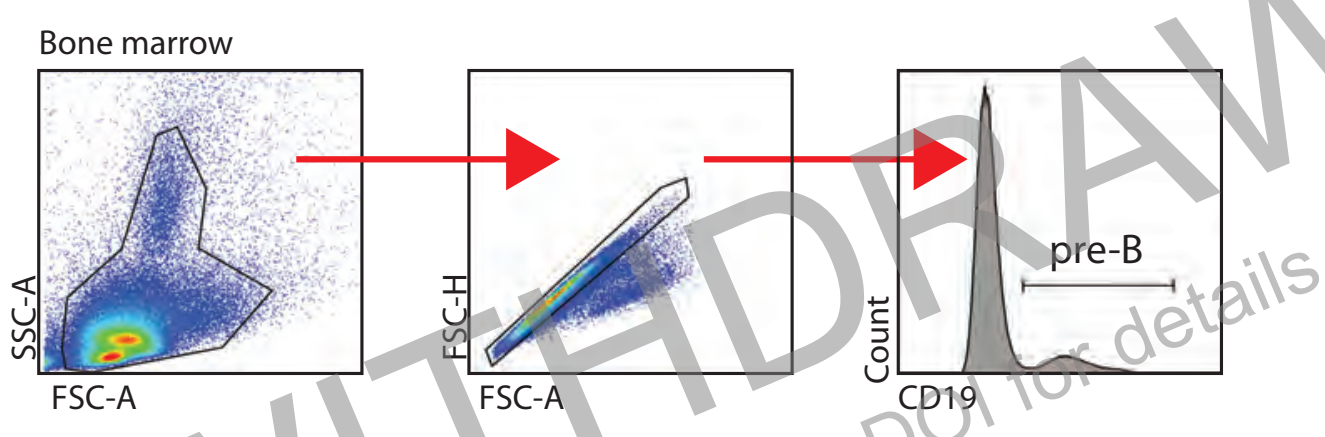

C

Bone marrow

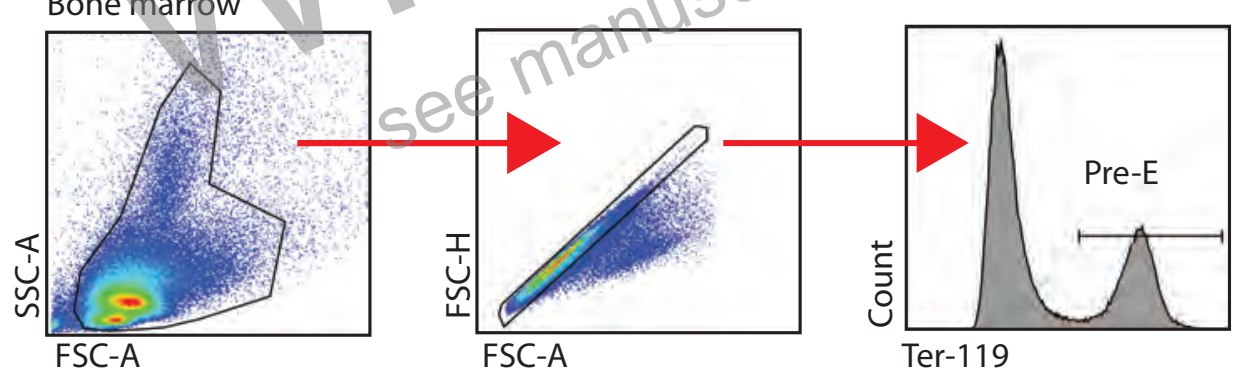

D

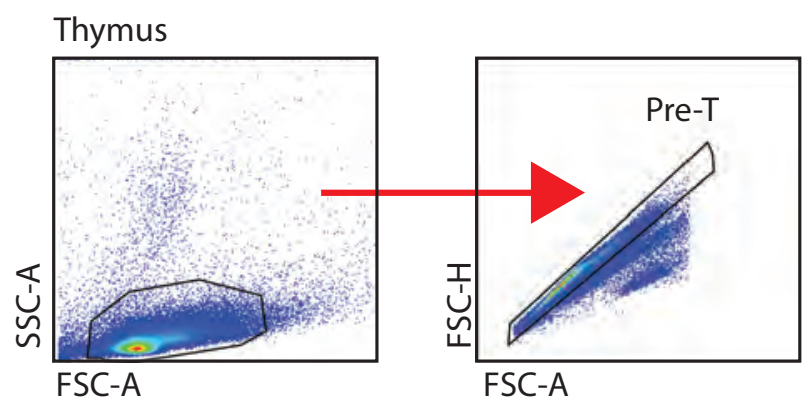

Figure S2: Flow cytometry gating strategies

Identification of LSK cells (A), pre-B cells (B), pre-E cells (C) and pre-T cells (D) by flow cytometry for Figures 2, Figure 5C, 5G \& 5H \& Figure S3. Lineage markers were not required to identify thymic $T$ cells because $T$ cells make up $>98 \%$ of total thymocytes. 
A
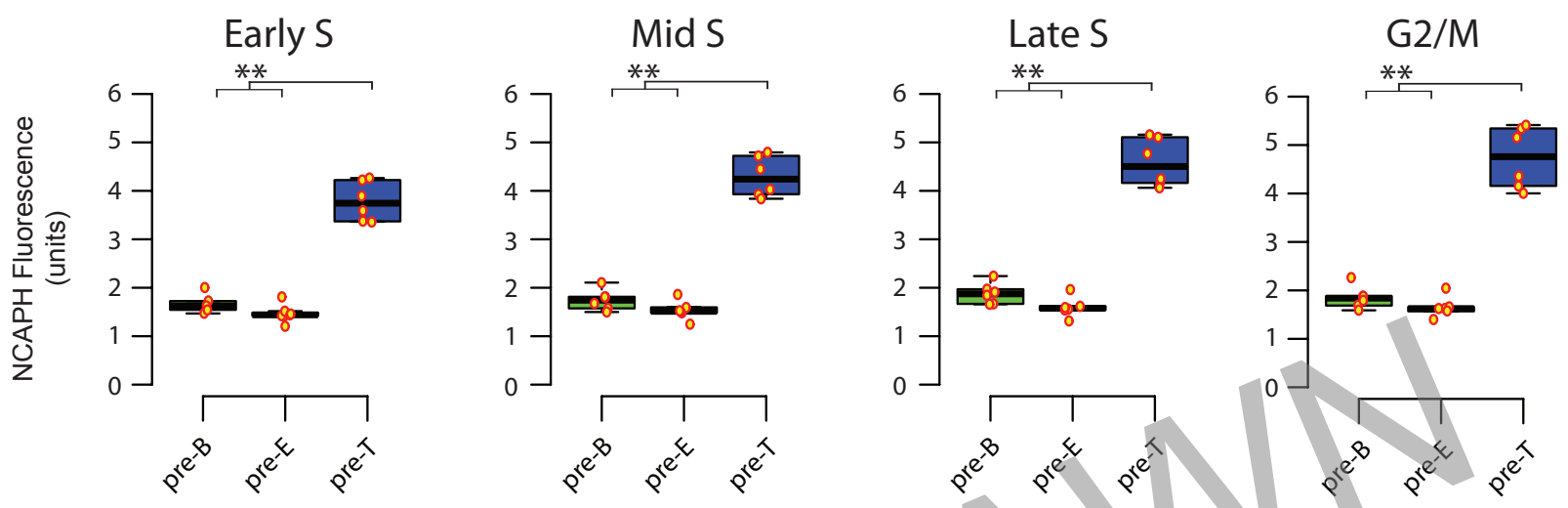

B
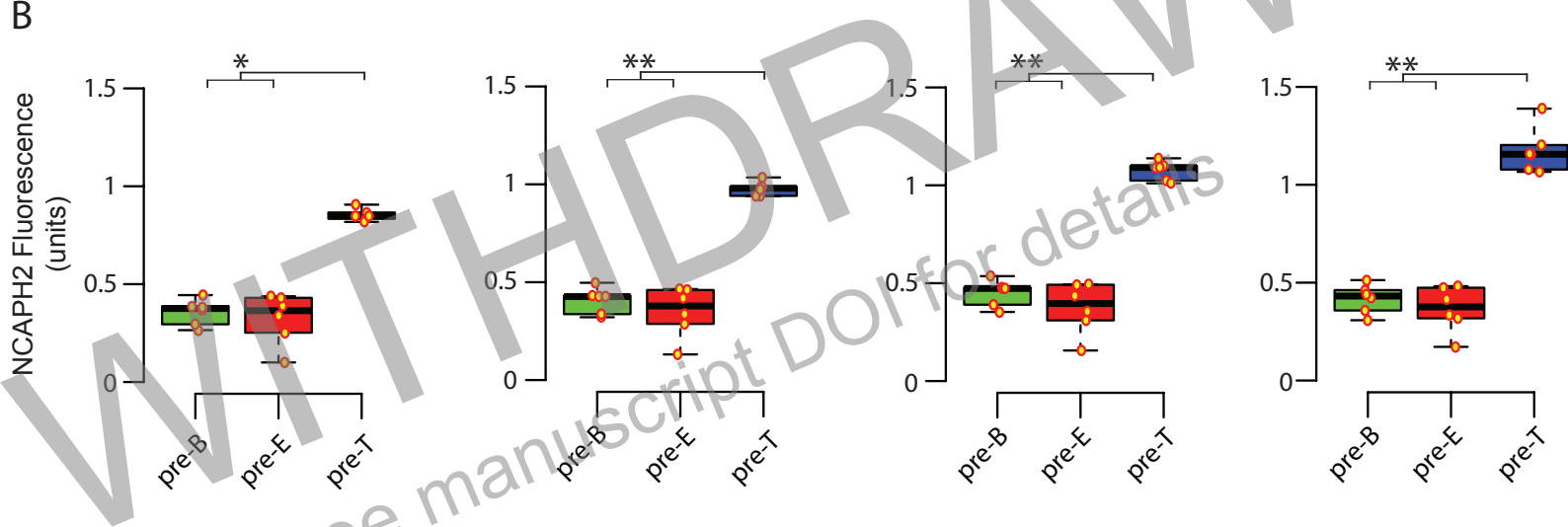

Figure S3: T cells express higher levels of Ncaph and Ncaph2 throughout the S/G2/M phases

Cells were pre-gated as shown in Figure S2, then assigned to early $S$ phase, mid S phase, late $S$ phase, or $\mathrm{G} 2 / \mathrm{M}$ based on their DNA content. Mean mClover fluorescence was calculated for Ncaph (A) or Ncaph2 (B) from at least 1000 cells per data point, and background fluorescence was subtracted. $n=6$ biological replicates from two independent experiments per condition. LSK cells were not analysed as they were present at numbers insufficient to obtain sufficient data for each cell cycle sub-phase. * indicates significant differences between conditions at $p<1 \times 10^{-6}$, ${ }^{* *}$ at $p<1 \times 10^{-7}$, from one-way ANOVA with Tukey's HSD posthoc test. 


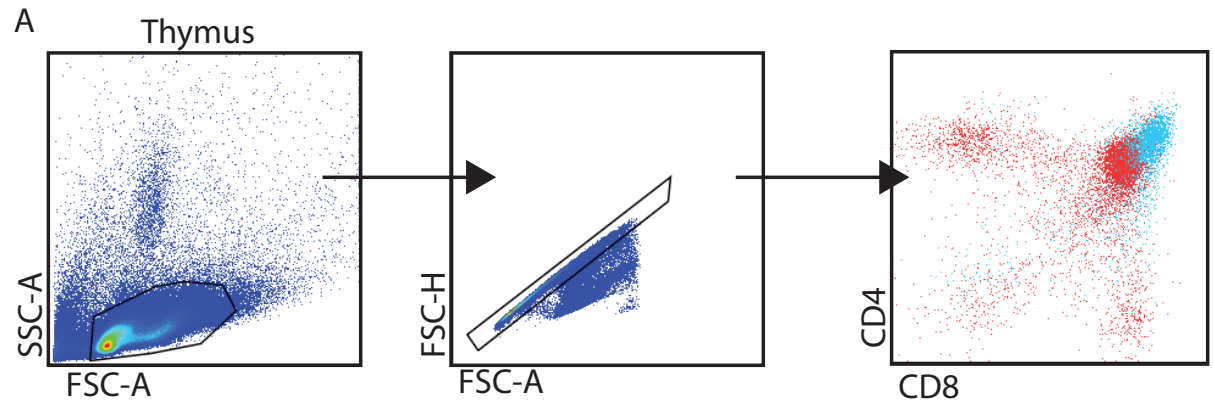

All cells

Mitotic cells

$\left(\mathrm{pH} 3 \mathrm{~S}_{10}\right)^{+}$

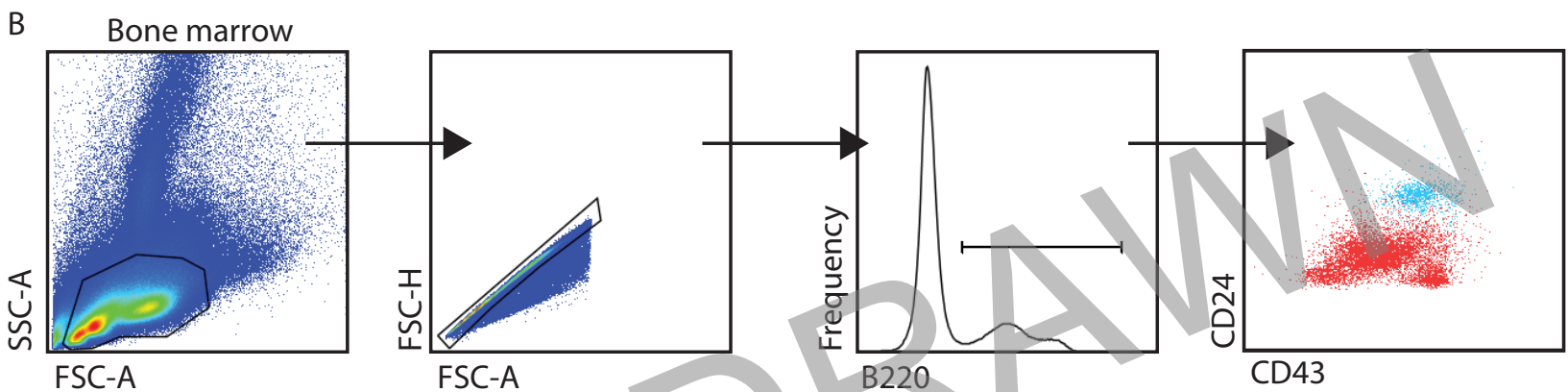

C Bone marrow

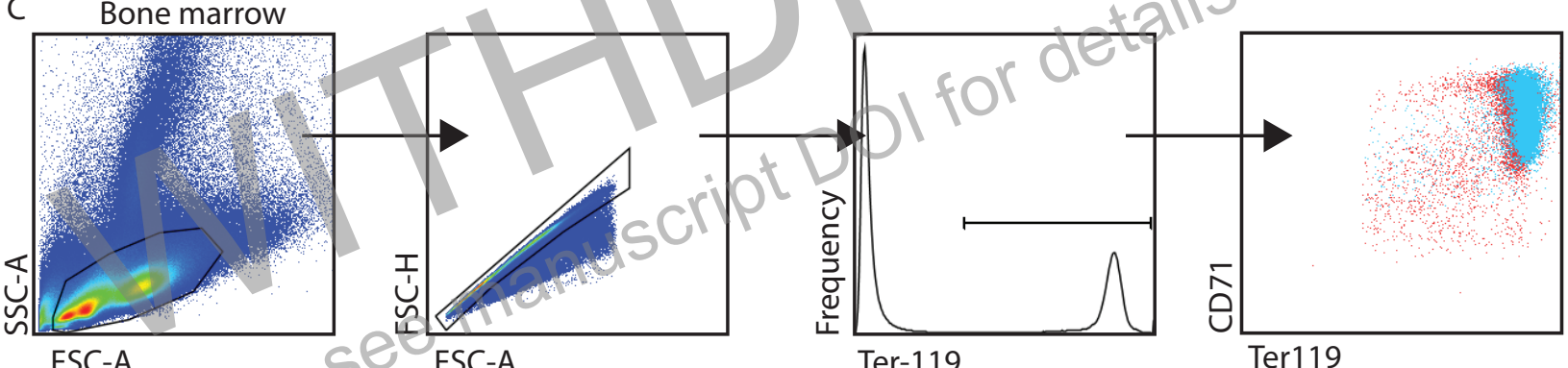

D Bone marrow

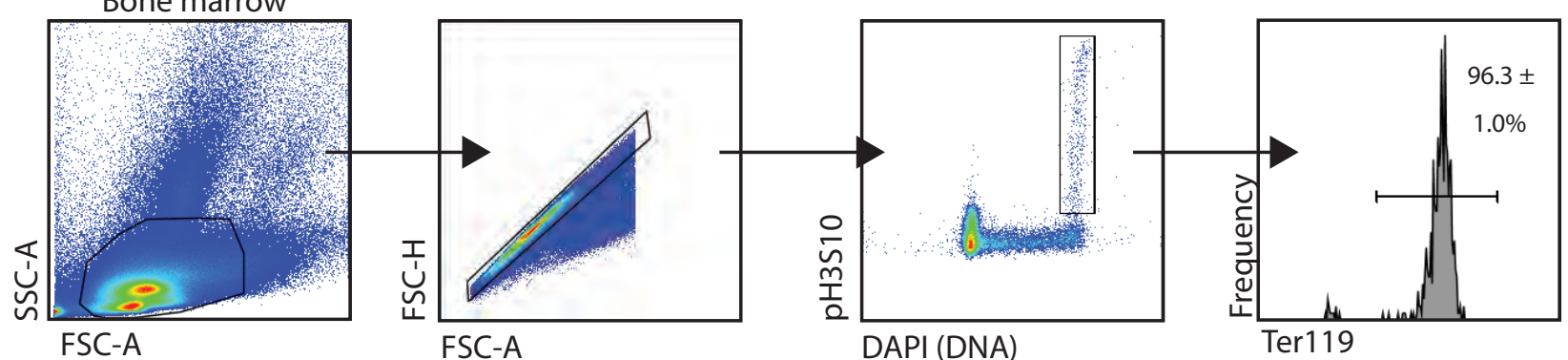

E Thymus

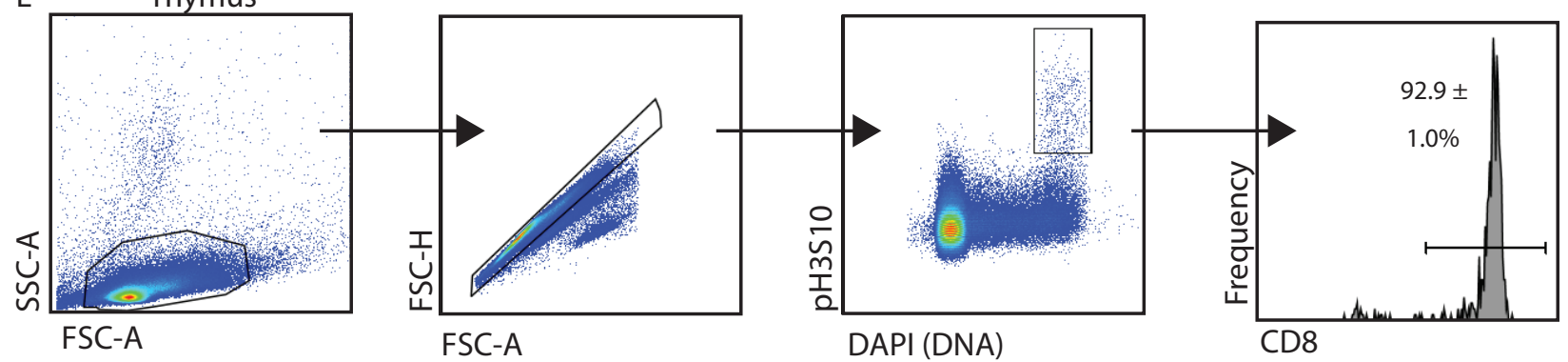

Figure S4: Developmental staging of mitotic cells within haematopoietic tissue

Immunophenotyping of mitotic cells. Each population was stained with antibodies against cell surface developmental markers and the intracellular mitotic marker $\mathrm{pH} 3 \mathrm{~S} 10$. (A - C) the developmental distribution of mitotic cells within the pre-T (thymocyte, A), pre-B $\left(B 220^{+}, \mathbf{B}\right)$,

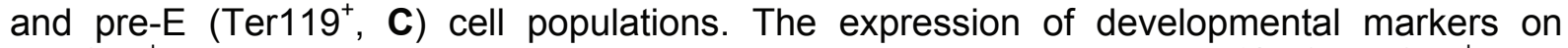
$\mathrm{pH} 3 \mathrm{~S} 10^{+}$mitotic cells is shown in blue, relative to all cells in red. D. $96.3 \%$ of $\mathrm{pH} 3 \mathrm{~S}_{10}{ }^{+}$cells express the erythroid marker Ter119. E. 92.9\% of mitotic thymocytes express the $\mathrm{T}$ cell marker CD8. Percentages and standard deviations in panels $D$ and $E$ are from $n=3$ mice. 
bioRxiv preprint doi: https://doi.org/10.1101/2020.11.04.367847; this version posted November 4, 2020. The copyright holder for this

preprint (which was not certified by peer review) is the author/funder, who has granted bioRxiv a license to display the preprint in perpetuity. It is made available under aCC-BY-NC 4.0 International license.

A
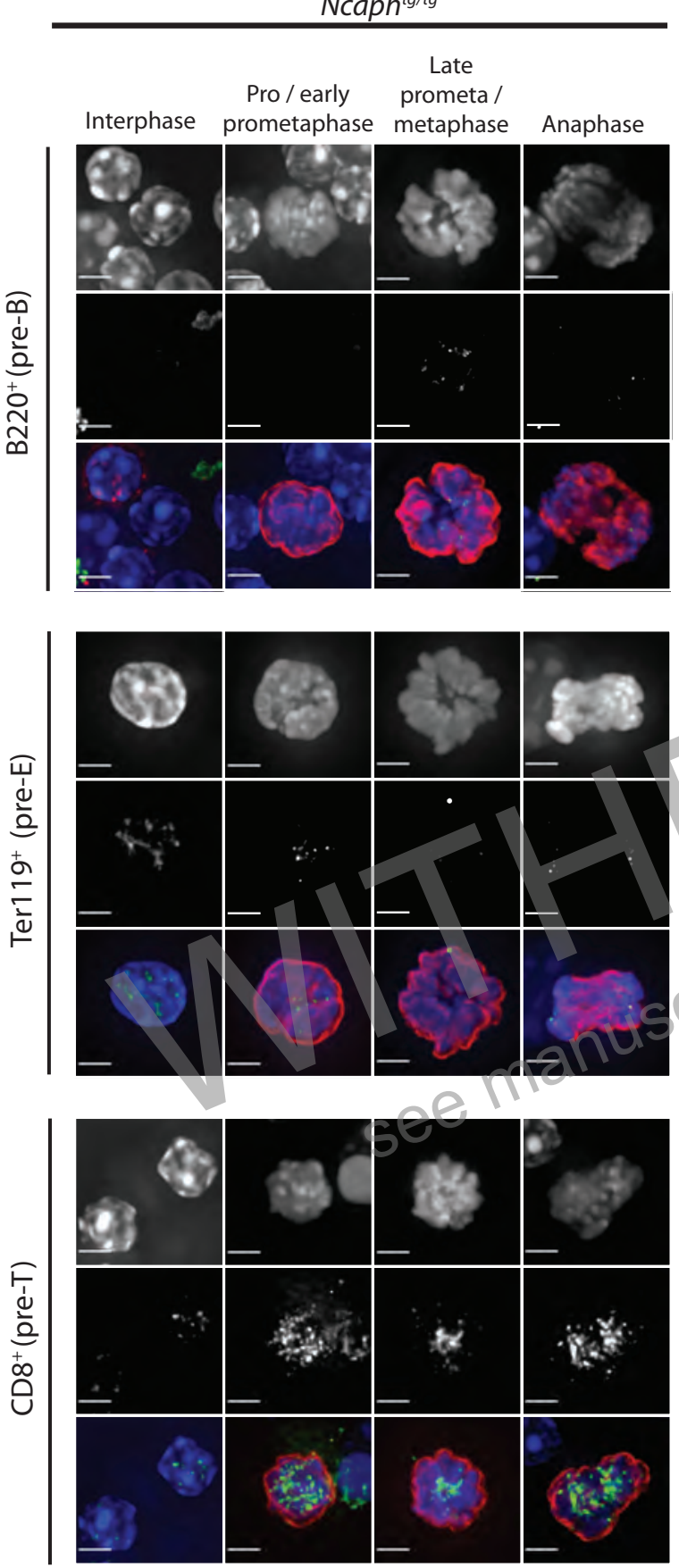

B

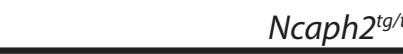

Interphase prometaphase metaphase Anaphase
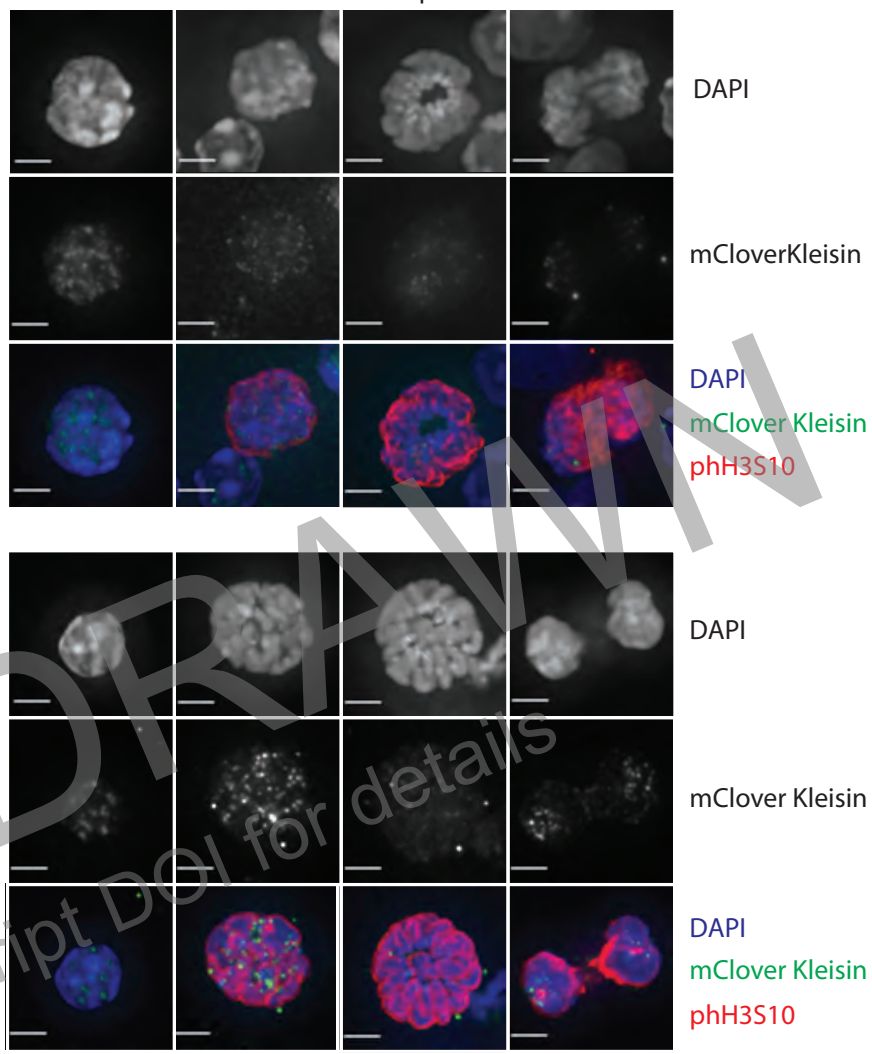

DAPI

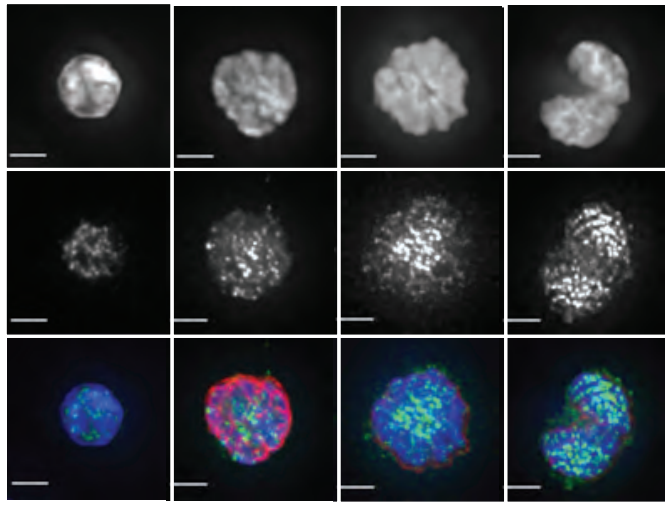

DAP

mClover Kleisin

DAPI

mClover Kleisin phH3S10

mClover Kleisin

DAPI

mClover Kleisin phH3S10

Figure S5: Ncaph and Ncaph2 are enriched on mitotic chromatin in pre-T cells compared to pre-E and pre-B cells

Images show maximum intensity projections from the same cells represented in Figures 3 and S7, with DAPI and mClover channels shown separately. To enable comparison of mClover intensity between cell types, signal intensity was adjusted for optimal visualisation in the pre-T cell late prometaphase / metaphase condition, and then images of other cell types and mitotic subphases were processed in an identical manner. A. Ncaph-mClover ${ }^{\text {tg/tg }}$ B. Ncaph2-mClover ${ }^{\text {tg/tg }}$. Scale bar $=3 \mu \mathrm{m}$. 
bioRxiv preprint doi: https://doi org/10.1101/202011.04.367847: this version posted November 4, 2020. The copyright holder for this preprint (which was not certified by peer review) is the author/funder, who has granted bioRxiv a license to display the preprint in perpetuity. It is made available under aCC-BY-NC 4.0 International license.

A

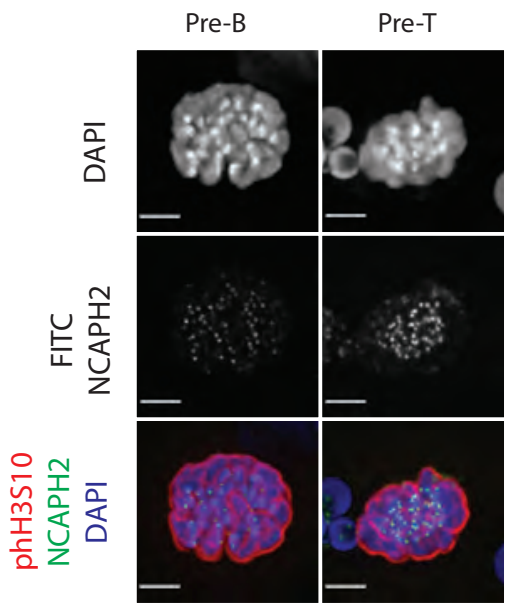

B

$n=38 \quad 36$

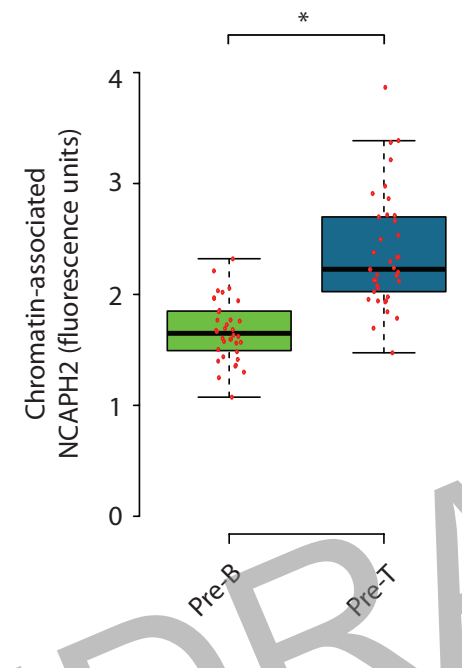

Figure S6: Elevated Ncaph2 protein on $T$ cell mitotic chromosomes from nontransgenic animals

A. Images of prometaphase cells from wildtype mice probed with antibodies against Ncaph2 and $\mathrm{pH} 3 \mathrm{~S} 10$ and stained with DAPL.DAPI fluorescence was used to segment mitotic chromatin in 3D. Erythroid cells were not measured in this experiment. Scale bar $=3 \mu \mathrm{m} \mathbf{B}$. Quantification of Ncaph2 fluorescence within DAPI stained regions of prometaphase cells. * indicates significant difference at $p<1 \times 10^{-9}$ from an unpaired two-tailed t-test. 
bioRxiv preprint doi: https://doi.org/10.1101/2020.11.04.367847; this version posted November 4, 2020. The copyright holder for this preprint (which was not certified by peer review) is the author/funder, who has granted bioRxiv a license to display the preprint in perpetuity. It is made available under aCC-BY-NC 4.0 International license.

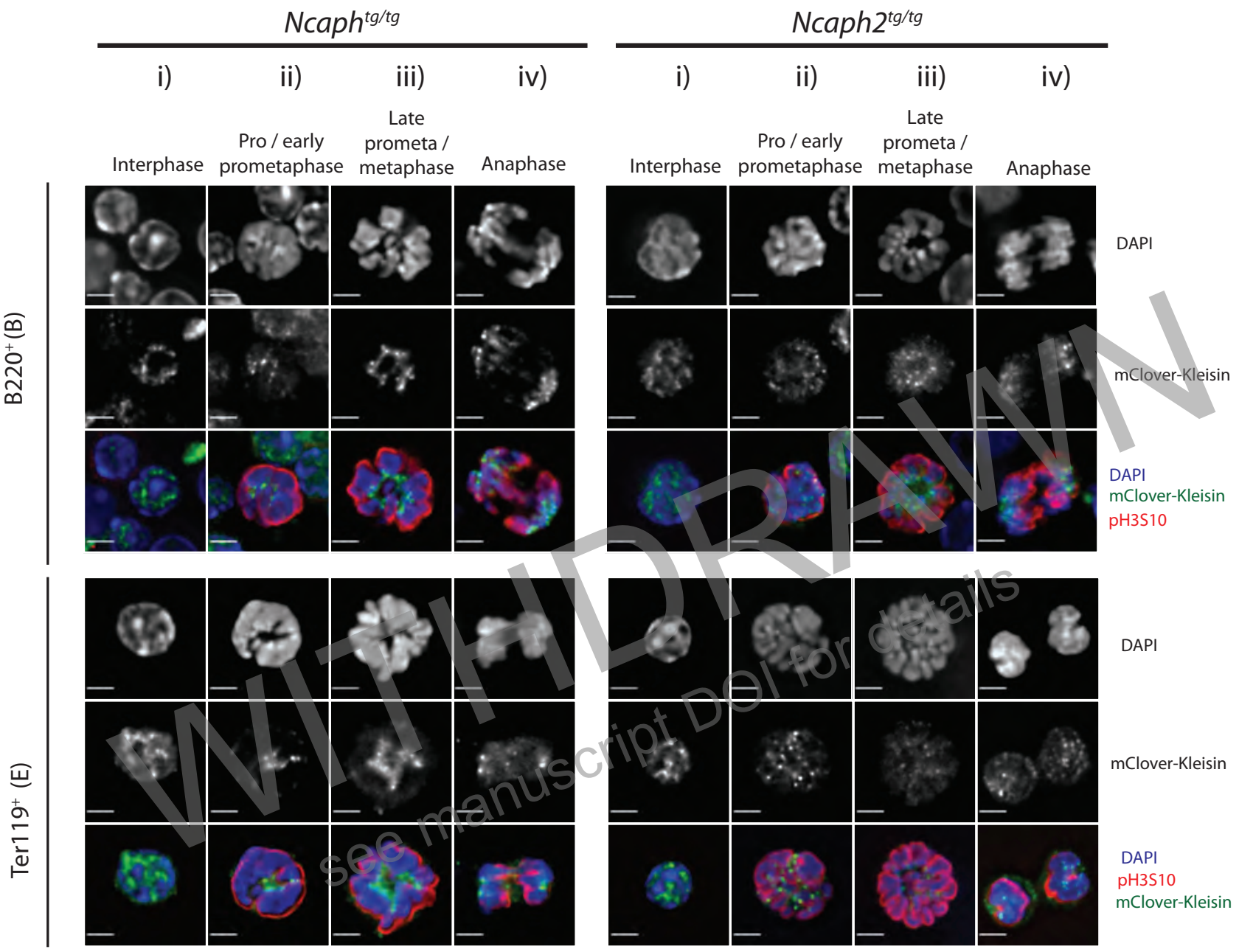

Figure S7: Condensin localisation during haematopoietic mitoses.

Representative immunofluorescence images of pre-B $\left(B 220^{+}\right)$and pre-E (Ter-119 $)$cells during interphase and different mitotic subphases (i) to iv) from $N$ caph $^{\text {tg/tg }}$ (A) and $N$ caph $2^{\text {tg/tg }}$ (B) animals. Representative images from pre-T cells are shown in Figure 3 . Signal from the mClover/488 channel was adjusted in these images to enable kleisin localisation to be visualised across diverse expression levels. For comparison, maximum-intensity projection images from the same cells without signal adjustment are shown in Figure S5. Images show single z-planes, scale bar $3 \mu \mathrm{m}$. A large majority of $\mathrm{pH} 3 \mathrm{~S} 10$ positive cells was in early or late prometaphase (images representative of $>30$ cells per condition). Anaphase cells were extremely rare (images representative of 1 to 5 cells per condition). 
A

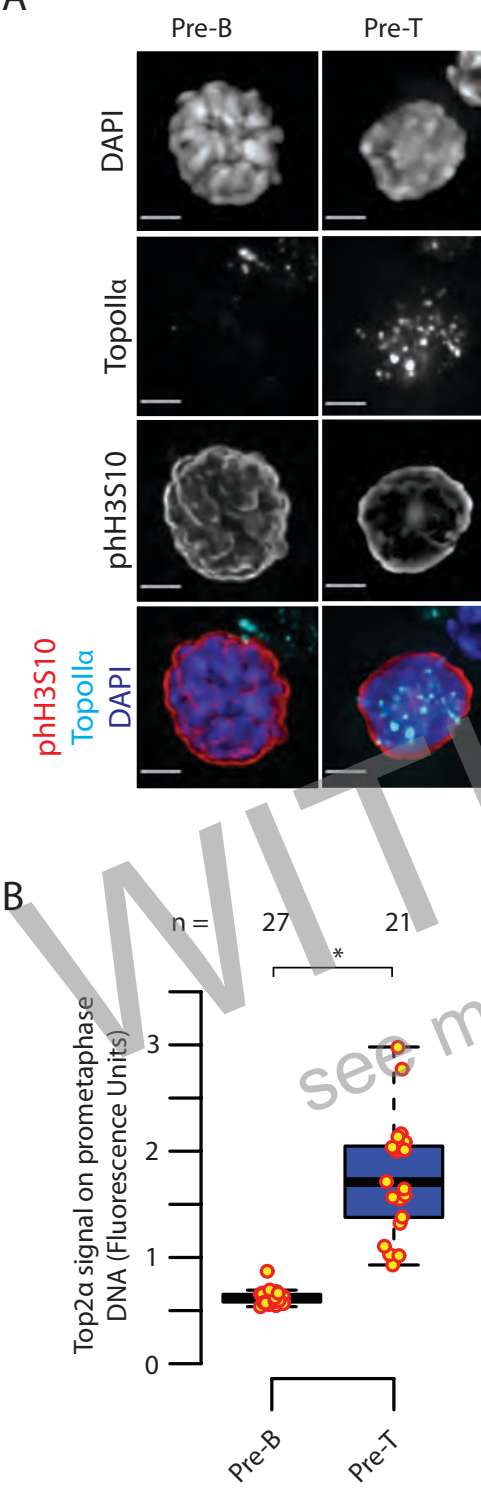

C
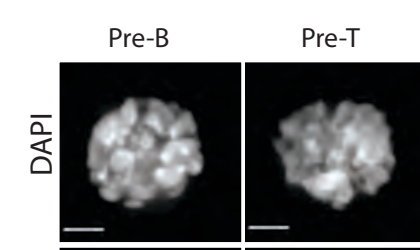

ำ
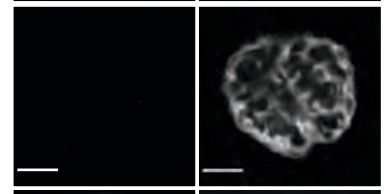

은
m
$\frac{c}{2}$

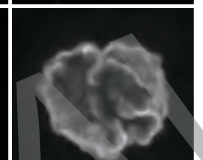

$\mathrm{D}$

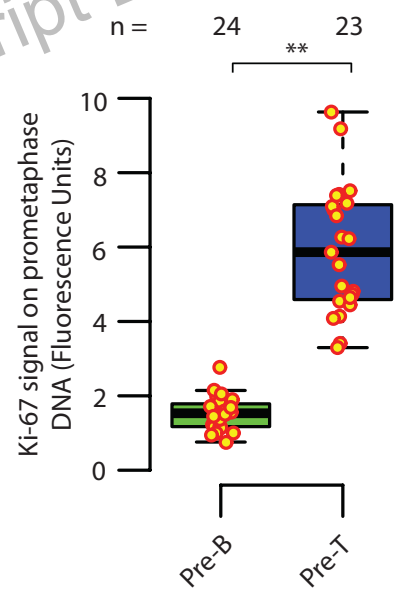

Figure S8: Quantification of TOP2A and Ki67 on prometaphase lymphocyte precursors

Immunofluorescence images of prometaphase pre-B and pre-T cells from wildtype mice probed with antibodies against Top2 $\alpha$ (A) or Ki67 (C) and pH3S10 (both). Erythroid cells were not studied in this experiment. Scale bar $=3 \mu \mathrm{m}$. B \& D. Quantification of immunofluorescence signal on mitotic chromatin. * indicates significant difference at $p<1 \mathrm{x}$ $10^{-9}{ }^{* *}$ at $p<1 \times 10^{-10}$, from two-tailed unpaired t-tests. 
bioRxiv preprint doi: https:/doi.org/10.1101/202011.04.367847: this version posted November 4, 2020. The copyright holder for this preprint (which was not certified by peer review) is the author/funder, who has granted bioRxiv a license to display the preprint in perpetuity. It is made available under aCC-BY-NC 4.0 International license.

A

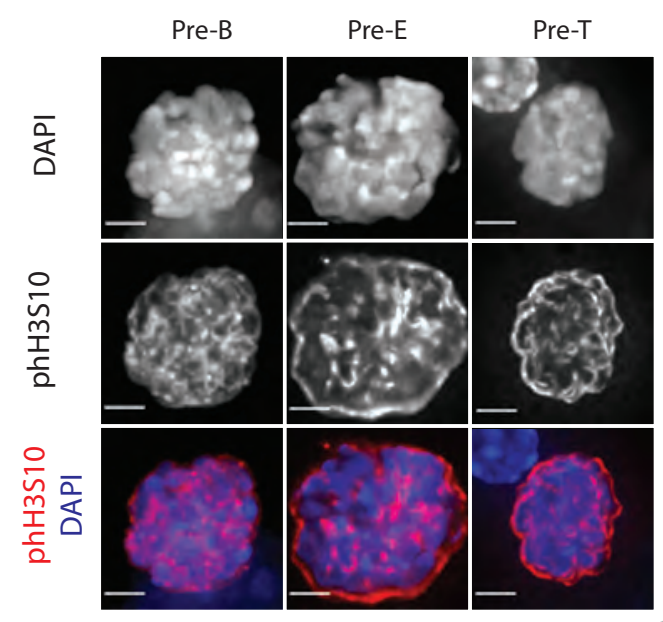

B

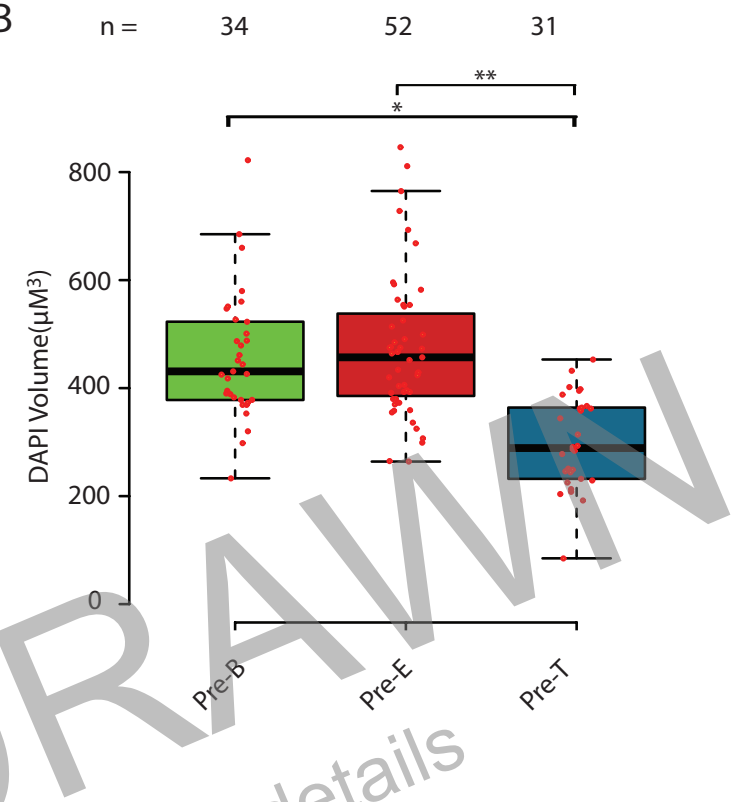

110 to

Figure S9: Hypercompaction of mitotic chromatin in thymic T cells following colcemid exposure in vivo

A. Images of prometaphase cells from B cell (pre-B; B220+), Erythroid (pre-E; Ter119+) and $\mathrm{T}$ cell (pre-T; CD8+) populations magnetically purified from bone marrow and thymus of wildtype mice. Cells were attached to slides using cytospin, in contrast to Figure 3 where cells were allowed to settle on coverslips. Colcemid solution was injected into the intraperitoneal cavity 30 minutes before euthanasia and tissue harvest. Scale bar $=3 \mu \mathrm{m}$ B. Prometaphase DNA volume measured by segmentation of DAPI fluorescence in cell populations shown in panel $A$. * indicates significant differences between conditions at $p<1$ $x 10^{-6},{ }^{* *}$ at $p<1 \times 10^{-7}$, from one-way ANOVA with Tukey's HSD posthoc test. 


\begin{tabular}{|l|c|c|c|c|}
\cline { 2 - 5 } \multicolumn{2}{c|}{} & \multicolumn{2}{c|}{ Thymus SMC4 IP / IgG } & \multicolumn{2}{c|}{ Bone Marrow SMC4 IP / IgG } \\
\cline { 2 - 5 } \multicolumn{1}{c|}{ Log $_{2} \mathrm{FC}$} & $\mathrm{p}$ value & Log $_{2} \mathrm{FC}$ & $\mathrm{p}$ value \\
\hline NCAPG & 6.07 & $4.7 \mathrm{E}-08$ & 0.59 & 0.28 \\
\hline SMC2 & 6.59 & $2.2 \mathrm{E}-07$ & 4.07 & $3.3 \mathrm{E}-07$ \\
\hline SSSCA1 & 6.00 & $2.6 \mathrm{E}-07$ & 2.23 & 0.04 \\
\hline SMC4 & 6.81 & $3.3 \mathrm{E}-07$ & 4.88 & $1.3 \mathrm{E}-05$ \\
\hline NCAPH & 8.14 & $3.3 \mathrm{E}-07$ & 3.57 & $1.1 \mathrm{E}-04$ \\
\hline NCAPD2 & 8.29 & $3.4 \mathrm{E}-07$ & 0.48 & 0.52 \\
\hline PANX1 & 4.49 & $1.4 \mathrm{E}-05$ & 5.65 & $7.0 \mathrm{E}-07$ \\
\hline ACRV2B & 4.18 & $1.8 \mathrm{E}-05$ & 0.14 & 0.87 \\
\hline MVP & 4.36 & $9.3 \mathrm{E}-05$ & 6.79 & $6.3 \mathrm{E}-07$ \\
\hline ZMYM4 & 5.18 & $6.0 \mathrm{E}-04$ & -1.21 & 0.02 \\
\hline DDX31 & 4.55 & $1.1 \mathrm{E}-03$ & 0.09 & 0.91 \\
\hline
\end{tabular}

B

\begin{tabular}{|l|c|c|c|c|}
\cline { 2 - 5 } \multicolumn{1}{c|}{} & \multicolumn{2}{c|}{ Bone Marrow SMC4 IP / IgG } & \multicolumn{2}{c|}{ Thymus SMC4 IP / IgG } \\
\cline { 2 - 5 } \multicolumn{1}{c|}{} & Log $_{2}$ FC & p value & Log $_{2}$ FC & Pvălue \\
\hline MVP & 6.79 & $6.3 \mathrm{E}-07$ & 4.35 & $9.2 \mathrm{E}-05$ \\
\hline PANX1 & 5.66 & $7.0 \mathrm{E}-07$ & 4.49 & $1.42 \mathrm{E}-05$ \\
\hline MYO18A & 4.35 & $5.0 \mathrm{E}-06$ & 0.14 & 0.81 \\
\hline C4B & 4.80 & $9.0 \mathrm{E}-05$ & 2.82 & $7.6 \mathrm{E}-05$ \\
\hline SMC4 & C4.88 & $1.3 \mathrm{E}-05$ & 6.59 & $2.2 \mathrm{E}-07$ \\
\hline SMC2 & 4.70 & $3.0 \mathrm{E}-05$ & 6.81 & $3.3 \mathrm{E}-07$ \\
\hline MFAP4 & 4.21 & $5.6 \mathrm{E}-05$ & 3.04 & $4.2 \mathrm{E}-04$ \\
\hline
\end{tabular}

C IP

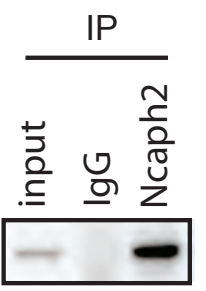

Figure S10 Tissue-specific interaction of $11 \mathrm{~S}$ condensin I subunits with SMC4

A. Table listing all proteins significantly enriched $\left(p<0.01, \log _{2} F C>4\right)$ following anti-SMC4 immunoprecipitation from thymic whole cell extract relative to lgG control. Protein enrichment was determined by Mass Spectrometry followed by Label-Free Quantification. For comparison, $\log _{2}$ Fold Change (FC) and p-values from Bayes-moderated t-tests (Kammers et al. 2015) are shown for equivalent experiments from bone marrow whole cell extract. B. Proteins significantly enriched following immunoprecipitation of SMC4 from bone marrow whole cell extract, as described for panel A. Whether proteins that are not known members of the condensin complex are bona fide interactors was not a focus of the current study, and will require validation using independent methods. C. Western blot showing Ncaph2 immunoprecipitation from thymic whole cell extract, probed with an anti-Smc4 antibody. 